\title{
Ground-based water vapor raman lidar measurements up to the upper troposphere and lower stratosphere for long-term monitoring
}

\author{
T. Leblanc, I. S. McDermid, and T. D. Walsh \\ Table Mountain Facility, Jet Propulsion Laboratory, California Institute of Technology, Wrightwood, CA 92397, USA \\ Correspondence to: T. Leblanc (leblanc@tmf.jpl.nasa.gov)
}

Received: 18 May 2011 - Published in Atmos. Meas. Tech. Discuss.: 10 August 2011

Revised: 3 December 2011 - Accepted: 20 December 2011 - Published: 4 January 2012

\begin{abstract}
Recognizing the importance of water vapor in the upper troposphere and lower stratosphere (UTLS) and the scarcity of high-quality, long-term measurements, JPL began the development of a powerful Raman lidar in 2005 to try to meet these needs. This development was endorsed by the Network for the Detection of Atmospheric Composition Change (NDACC) and the validation program for the EOSAura satellite. In this paper we review the stages in the instrumental development, data acquisition and analysis, profile retrieval and calibration procedures of the lidar, as well as selected results from three validation campaigns: MOHAVE (Measurements of Humidity in the Atmosphere and Validation Experiments), MOHAVE-II, and MOHAVE 2009.

In particular, one critical result from this latest campaign is the very good agreement (well below the reported uncertainties) observed between the lidar and the Cryogenic FrostPoint Hygrometer in the entire lidar range 3-20 km, with a mean bias not exceeding $2 \%$ (lidar dry) in the lower troposphere, and $3 \%$ (lidar moist) in the UTLS. Ultimately the lidar has demonstrated capability to measure water vapor profiles from $\sim 1 \mathrm{~km}$ above the ground to the lower stratosphere with a precision of $10 \%$ or better near $13 \mathrm{~km}$ and below, and an estimated accuracy of $5 \%$. Since 2005 , nearly 1000 profiles have been routinely measured, and since 2009 , the profiles have typically reached $14 \mathrm{~km}$ for one-hour integration times and $1.5 \mathrm{~km}$ vertical resolution, and can reach $21 \mathrm{~km}$ for 6-h integration times using degraded vertical resolutions.

These performance figures show that, with our present target of routinely running our lidar two hours per night, 4 nights per week, we can achieve measurements with a precision in the UTLS equivalent to that achieved if launching one $\mathrm{CFH}$ per month.
\end{abstract}

\section{Introduction}

Due to its radiative, chemical, and thermodynamic properties, water vapor has long been identified as a key constituent of the atmosphere. The water vapor molecule strongly absorbs infrared radiation and in the troposphere it is therefore a primary greenhouse gas. In the stratosphere it is produced by methane oxidation thus linking it to ozone chemistry. It was shown that a global increase in lower stratospheric $\mathrm{H}_{2} \mathrm{O}$ mixing ratio similar to that observed locally since 1981 (Oltmans and Hofmann, 1995; Hurst et. al., 2011a) would contribute to a surface warming reaching $40 \%$ of that responsible from $\mathrm{CO}_{2}$ increases over the same period (Forster and Shine, 1999). The resulting lower stratospheric cooling would be of same order of magnitude as that caused by changes in ozone concentrations. Therefore, to fully understand, quantify, and predict future water vapor-related radiative and chemical processes impacting climate change, high accuracy water vapor measurements throughout the troposphere and stratosphere are required (typically $3-10 \%$ ). Despite water vapor's recently observed trends (e.g., Hurst et al., 2011a), many instruments today cannot achieve the required accuracy without thorough calibration and validation.

To help address this issue, the Network for the Detection of Atmospheric Composition Change (NDACC, formerly known as NDSC) included water vapor Raman lidar in its suite of long-term monitoring techniques. A high capability water vapor Raman lidar was therefore built at the Jet Propulsion Laboratory (JPL) Table Mountain Facility (TMF) in California $\left(34.4^{\circ} \mathrm{N}, 117.5^{\circ} \mathrm{W}\right.$, elevation $\left.2285 \mathrm{~m}\right)$, with the primary objective of reaching the upper troposphere and lower stratosphere (UTLS) with the best possible accuracy 
(5\% or better) (Leblanc et al., 2008a). The instrument, referred to as "TMW" in the remainder of this paper, has been optimized over the years and is now capable of producing routine measurements of water vapor between $4 \mathrm{~km}$ and 15 $20 \mathrm{~km}$ with a precision of $10 \%$ or better, and $5 \%$ accuracy.

The present paper reviews the TMW instrumentation setup and optimization over the past five years, describes the data acquisition and analysis, the calibration procedures, and presents results from the latest validation campaign MOHAVE-2009, which best characterize the present performance of the system. A brief review of the Raman lidar technique is first given in Sect. 2. The instrument technical description and achievements, including multiple upgrades over the period 2005-present and the various stages of its validation, are presented in Sects. 3 and 6. The lidar data analysis and profile retrieval are described in Sect. 4. Results from the most recent validation campaign MOHAVE-2009 are presented in Sect. 7. The last section reviews additional considerations chosen to guarantee long-term stability of the routine measurements for future use by NDACC.

\section{Water vapor raman lidar measurement principle}

The Raman lidar measurement technique is relatively simple in principle and easy to implement (Melfi et al., 1969; Vaughan et al., 1988; Sherlock et al., 1999a). A laser pulse is emitted into the atmosphere and scattered by the molecules and particles. A fraction of the laser light is collected back on the ground with a telescope, where it is geometrically and spectrally separated, and sampled in time (i.e., distance). In the case of the Raman technique, the light scattered by a specific molecule is shifted by an amount that depends on the energy difference between its vibrational and/or rotational states (Hinckley, 1976; Measures, 1992). For water vapor, the Stokes Q branch occurring in the $\mathrm{OH}$-stretching band near the frequency shift of $3654 \mathrm{~cm}^{-1}$ is most often used. The water vapor Raman technique also makes use of scattering by a reference molecule with a well-known mixing ratio throughout the altitude range of interest. In the case of the well-mixed and abundant gas nitrogen, the strongest Stokes Q-branch occurring at a frequency shift of $v_{1} \approx 2330 \mathrm{~cm}^{-1}$ (transition from the ground-state to the first vibrational state) is normally used. The fraction of the total energy scattered at the shifted wavelengths is typically three orders of magnitude smaller than that for elastic scattering. The backscatter coefficient can be expressed as the product of the molecule's Raman backscatter cross-section $\sigma$ and its number density $N$, which leads to the following form of the lidar equation:

$$
\begin{aligned}
& P_{\mathrm{M}}(r)=P_{\mathrm{E}} \kappa_{\mathrm{M}} \frac{O_{\mathrm{M}}(r) A_{\mathrm{M}} \delta r}{r^{2}} \sigma_{\mathrm{M}}(r) N_{\mathrm{M}}(r) \\
& \exp \left[-\int_{0}^{r}\left(\alpha_{\mathrm{E}}\left(r^{\prime}\right)+\alpha_{\mathrm{M}}\left(r^{\prime}\right)\right) d r^{\prime}\right]
\end{aligned}
$$

$P_{\mathrm{E}}$ is the number of photons emitted, per laser shot (at emission wavelength $\lambda_{\mathrm{E}}$ ). $r$ is the distance between the laser and the backscattering layer being considered. $\delta r$ is the thickness of the backscattering layer being considered. $P_{\mathrm{M}}$ is the number of photons detected, per laser shot, at the wavelength shifted by the target molecule $\mathrm{M}\left(\mathrm{M}=\mathrm{H}_{2} \mathrm{O}\right.$ or $\left.\mathrm{N}_{2}\right) . \kappa_{\mathrm{M}}$ is the overall optical transmittance and quantum efficiency for the channel corresponding to the molecule $\mathrm{M}$. $\mathrm{O}_{\mathrm{M}}$ is the telescope field-of-views and laser beam overlap factors for the channel corresponding to the molecule M. $A_{\mathrm{M}}$ is the receiving area coupled with the channel corresponding to the molecule $\mathrm{M}$.

The terms $\alpha_{\mathrm{E}}$, and $\alpha_{\mathrm{M}}$ are the total atmospheric transmittances along the beam path from the lidar to the scattering layer and back to the receiver channel corresponding to the molecule $\mathrm{M}$. The above equation describes the collected signal in one individual channel with ideal noise-free instrumentation. In reality, the total acquired signal is a combination of the collected light backscattered in the atmosphere and noise originating from both residual sky background light and from the instrumentation. The signal can also be subject to nonlinearity, especially at very high-count rates. After noise extraction and correction for non-linearities, the ratio of the corrected signals $\bar{P}$ collected in the water vapor $\left(\mathrm{M}=\mathrm{H}_{2} \mathrm{O}\right)$ and nitrogen $\left(\mathrm{M}=\mathrm{N}_{2}\right)$ channels can be written:

$R(r)=\frac{\bar{P}_{\mathrm{H}_{2} \mathrm{O}}(r)}{\bar{P}_{\mathrm{N}_{2}}(r)}=\kappa_{\mathrm{eff}}(r) \kappa_{\mathrm{O}}(r) \kappa_{\sigma}(r) \kappa_{\alpha}(r) \frac{\mathrm{N}_{\mathrm{H}_{2} \mathrm{O}}(r)}{\mathrm{N}_{\mathrm{N}_{2}}(\mathrm{r})}$

$\kappa_{\text {eff }}$ is a constant expressing the ratio of all the optical and quantum efficiencies of the receivers as well as other constant terms,

$\kappa_{\mathrm{O}}(r)$ is the ratio of the overlap functions of the nitrogen and water vapor channels,

$\kappa_{\sigma}(r)$ is the ratio of the nitrogen and water vapor Raman cross-sections,

$\kappa_{\alpha}(r)$ is the ratio of the particulate extinction along the return path of the beam at the nitrogen and water vapor wavelengths (often referred to as "extinction differential").

The extinction terms can be separated into molecular and particulate extinction. Molecular extinction can be calculated for each channel prior to computing the ratio $R(r)$ using climatological, modeled, or measured profiles of the air number density and the density of the atmospheric absorbers, leaving only the particulate extinction contribution in Eq. (2). This latter equation can be related to water vapor mixing ratio expressed as a function of number density:

$q(r)=0.781 \frac{\mathrm{N}_{\mathrm{H}_{2} \mathrm{O}}(r)}{\mathrm{N}_{\mathrm{N}_{2}}(r)}$

Replacing $q(r)$ into Eq. (2) and reverting yields:

$q(r)=\kappa_{\mathrm{eff}} \kappa_{\mathrm{O}}(r) \kappa_{\sigma}(r) \kappa_{\alpha}(r) R(r)$

Depending on the lidar instrument setup, the four multiplicative terms in front of the term $R(r)$ in Eq. (3) have a varying 
degree of dependency on altitude. Their estimation is known as the "lidar calibration", and is discussed in Sects. 4.2 and 7.

\section{Instrument initial setup (2005-2007)}

\subsection{Transmitter}

Throughout the development of the TMW lidar system (2005-present), the laser transmitter, telescope, and the data acquisition system have remained essentially unchanged. The laser is a high pulse energy Nd:YAG laser (Continuum) operating at $355 \mathrm{~nm}$ at a repetition rate of $10 \mathrm{~Hz}$. While specified to produce more than $900 \mathrm{~mJ}$ pulse ${ }^{-1}$, in long-term operation it consistently provides around $650 \mathrm{~mJ} \mathrm{pulse}^{-1}$. The beam is expanded $7.5 \mathrm{x}$ using a refractive beam-expander (CVI) before being steered into the atmosphere. Alignment of the laser to the receiving telescope is performed automatically and the program and mechanics of this part of the system have been fully described by Aspey et al. (2008). Figure 1 of this reference also shows the basic arrangement of the lidar transmitter and receiver telescope.

\subsection{Receiver}

TMW makes use of the vibrational Raman shift at $2330 \mathrm{~cm}^{-1}$ for nitrogen and $3654 \mathrm{~cm}^{-1}$ for water vapor, as mentioned in Sect. 2. For an emission at $355 \mathrm{~nm}$, this translates to receiving at $387 \mathrm{~nm}$ and $407 \mathrm{~nm}$ respectively. The primary telescope is a $91 \mathrm{~cm}$-diameter Newtonian telescope for the far-range channels supplemented by three (later four) $7.5 \mathrm{~cm}$ diameter refractive telescopes for the near range. The small receivers are each designed to detect only a single wavelength and, as shown in Fig. 1 (top), comprise a $7.5 \mathrm{~cm}$ fused silica lens (L1), a variable diaphragm field stop (FS), collimating and refocusing lenses sandwiching an interference filter (one each for $355 \mathrm{~nm}$ [F3], $387 \mathrm{~nm} \mathrm{[F1],} \mathrm{and} 407 \mathrm{~nm}$ [F2]). The received light is focused directly onto the photomultiplier (PMT) detector modules (P). Other than the addition of a fourth channel (very low intensity $355 \mathrm{~nm}$ for tropospheric aerosols information), the small receivers setup was basically unchanged since the lidar first light in 2005 .

Coupling of the large telescope to the receiver polychromator is one of the arrangements that was changed as the lidar evolved. These changes will be described in Sects. 6.1 and 6.3 A diagram of the initial design of the channels coupled out of the large telescope is shown in Fig. 1 (bottom). Light was sent from the telescope into the polychromator using a $1 \mathrm{~mm}$ diameter UV grade optical fiber (CeramOptec). The 0.22 numerical aperture of the fiber was matched to the $\mathrm{f} / 2.7$ focal ratio of the telescope and the diameter of the fiber also acted as a field-stop defining the field-of-view (fov) as $400 \mu \mathrm{rad}$. There were several reasons for choosing to use fiber coupling. It was not clear at the outset whether it would be required to install a chopper to counter signal-inducednoise. Should this have proved necessary, it would have been
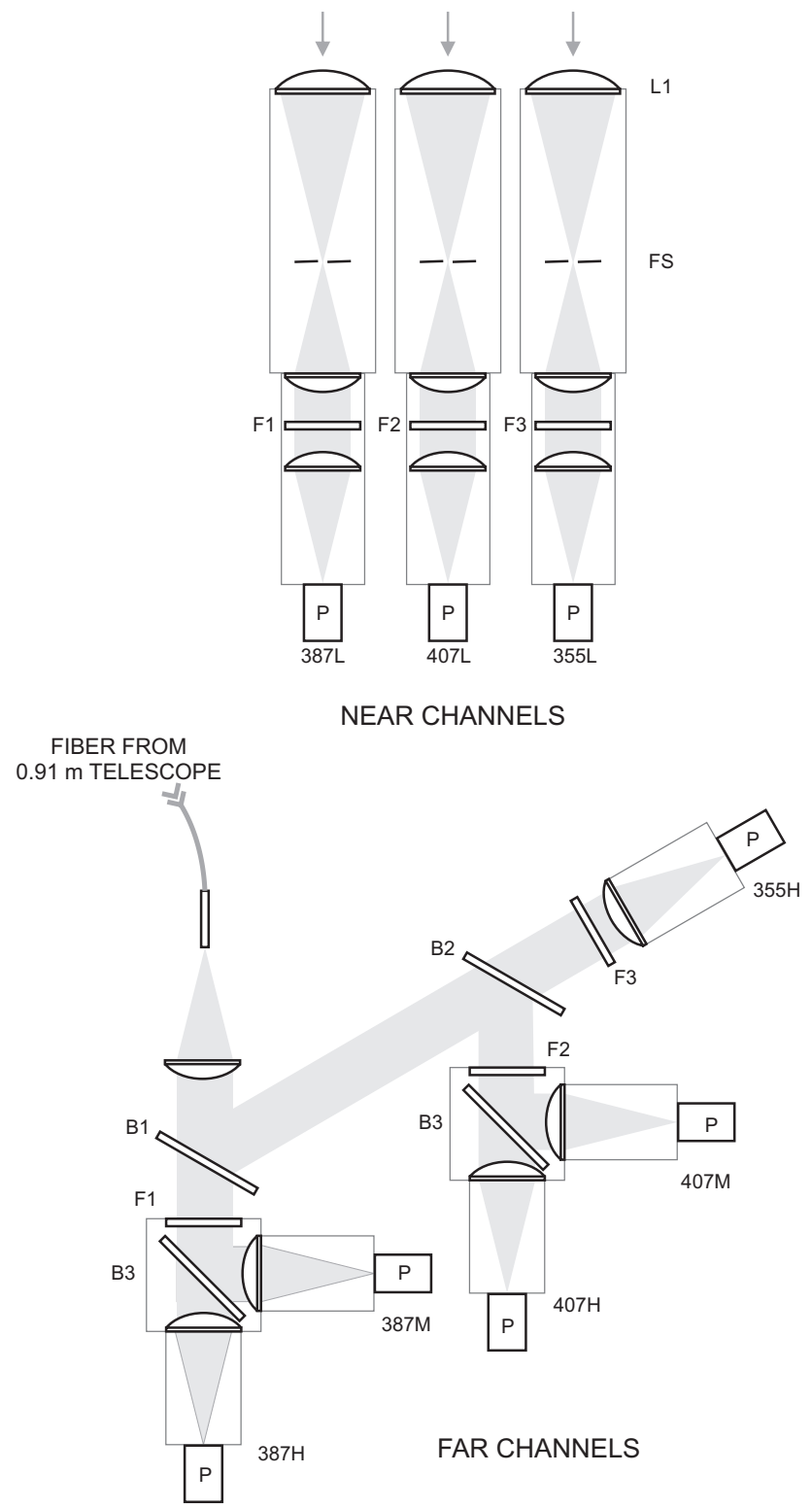

Fig. 1. TMW lidar receiver initial configuration, i.e., 2005-2007 for the five high- and mid-intensity channels, and 2005-present for the three low-intensity channels. A fourth low intensity channel, $355 \mathrm{~nm}$ extra-low intensity, was added in 2007.

much easier to implement with a fiber. Also, we have successfully used similar fibers in other lidar systems (e.g., McDermid et al., 1999) and they minimize obscuration in the Newtonian configuration. Referring to Fig. 1 (bottom), the light entering the polychromator from the fiber is collimated and then the first dichroic beamsplitter (B1) transmits $387 \mathrm{~nm}$ while reflecting $407 \mathrm{~nm}$ and $355 \mathrm{~nm}$. An interference filter (F1) further selects only $387 \mathrm{~nm}$ and then the signal is divided using an anti-reflection coated fused silica plate (B3) into two parts with intensity ratio approximately 99:1. Using these 99:1 dual channels allows signal non-linearities, i.e., 
saturation, to be corrected and dynamic range to be extended. Similarly, beamsplitter (B2) reflects $407 \mathrm{~nm}$ and transmits the remaining $355 \mathrm{~nm}$. As for the $387 \mathrm{~nm}$ channels, an interference filter (F2) is used to select only $407 \mathrm{~nm}$ and the signal is divided (B3) into high and medium intensity channels. Interference filter (F3) transmits only $355 \mathrm{~nm}$ onto a gated PMT.

In the original configuration, all 8 channels ( 5 channels from the large telescope and 3 from the small telescopes) utilized the same type PMT modules (Hamamatsu H5783P) except for the $355 \mathrm{~nm}$ high-intensity channel which used a bare R7400 PMT (Hamamatsu) in a home-built electronically gated base. This PMT was electronically gated to turn on at about $20 \mathrm{~km}$ in order to suppress some of the saturation and signal-induced-noise caused by the very high intensity Rayleigh returns from lower altitudes. All PMT signals were input to a series of photon counting multi-channelscalers (Licel Transient Recorder). The Licel units, triggered at $10 \mathrm{~Hz}$, collect the signal in 16384 bins of $7.5 \mathrm{~m}$ width each (dwell time of $50 \mathrm{~ns}$ ). The photon counts are then summed and stored into 5-min-integrated data files with a 75-m bin width, before being analyzed.

\section{Data analysis}

\subsection{Profile retrieval}

The signals from all 3 pairs of $387-407 \mathrm{~nm}$ channels are analyzed for the retrieval of water vapor $(3-20 \mathrm{~km})$ by our inhouse lidar analysis software LidAna, version 7.0. This version is the latest optimized version of the software which has been used for over a decade to analyze all existing JPL lidar products archived at NDACC. Temperature $(10-90 \mathrm{~km})$ and backscatter ratio $(4-40 \mathrm{~km})$ profiles can also be retrieved, though no routine temperature or aerosol product is currently derived from the TMW lidar signals (these products exist from the other JPL lidars). Nevertheless, preliminary temperature results obtained from TMW during the MOHAVE2009 campaign are shown in McGee et al. (2011).

For all TMW channels, the collected signals are first corrected for background noise. The raw signals are fitted over an altitude range where only noise is known to be present. For water vapor retrieval, a simple linear fit with a zero-slope (constant noise) is sufficient as no signal-induced noise is present in any of the Raman channels. At the bottom of the channels' useful range, signal non-linearities (pulse pile-up effect) are corrected either empirically using the method described in Donovan et al. (1993), or experimentally using the non-saturated signals from the lower intensity channels. The high intensity pair is optimized to provide water vapor measurements between $8 \mathrm{~km}$ and $20 \mathrm{~km}$. The useful range can be extended downward to $5 \mathrm{~km}$ with proper correction of saturation using the non-saturated low intensity pair coupled to the large telescope, and which provides valid measurements be- tween $4 \mathrm{~km}$ and $8 \mathrm{~km}$. The two pairs of channels coupled out of the large telescope were designed so that the contribution of their overlap functions in Eq. (3) is nearly independent of height above $7 \mathrm{~km}$. Below this altitude, this contribution is occasionally verified experimentally using the pair of channels coupled out of the small telescopes. The correction however is not used in the normal data processing since it sometimes yields larger errors than if we assume that the ratio of the overlap functions in the narrow field-of-view water vapor and nitrogen channels cancel out. This latter assumption is verified by simply comparing the profiles obtained from the narrow and wide field-of-view channels (see Fig. 3 later in this section). The low intensity pair of wide fov channels provides water vapor profiles between altitudes of $3 \mathrm{~km}$ ( $600 \mathrm{~m}$ above ground) and $7 \mathrm{~km}$, with a contribution of the overlap functions negligible down to the lowest useful data bins ( $2.8 \mathrm{~km}$ altitude).

In addition to background correction, saturation correction, and the optional overlap correction, the signals are corrected for atmospheric extinction along the laser beam path using the density profiles computed from the National Centre for Environmental Prediction (NCEP) temperature and pressure profiles interpolated at the measuring site. These profiles are made available on a daily basis to all NDACC participants at the NDACC Data Handling Center (http:// www.ndacc.org/). Though mostly negligible at these wavelengths, a correction for ozone absorption is further applied to all channels before water vapor is computed from the uncalibrated ratio following Eq. (3).

At this stage of the analysis, the signal ratios for each of the three $387 / 407 \mathrm{~nm}$ pairs of channels should be smoothed to mitigate the random noise due to photon counting. It is made using a height dependent smoothing scheme that limits random uncertainties to less than $10 \%$ at all altitudes except in the very highest altitude bins (14 km and above). A Kaiser filter with a fixed attenuation of $-50 \mathrm{~dB}$ is used to smooth the data (Kaiser and Reed, 1977). The attenuation is the only fixed input parameter of the filter. The other parameters (cutoff frequency and number of coefficients) are automatically computed as a function of height to provide a minimum impact of smoothing, yet insuring precision of $10 \%$ of better throughout the profile below about $14 \mathrm{~km}$. Above this altitude, the maximum number of points used for filtering is capped to 97 (7.2 km full-width), which causes precision to degrade from $10 \%$ up to $30 \%$. Vertical resolution is reported in the data files following the definition of the cutoff frequency of the filter. Figure 2 illustrates the effect of the signal filtering expressed as a function of the Kaiser filter's cutoff frequency and number of coefficients (top), and expressed as a function of the full-width at half-max (FWHM) of an Impulse Response (Dirac's Delta function) (bottom). Following the definition based on cutoff frequency, unsmoothed signals are reported with a vertical resolution of 150-m (two sampling bins, corresponding to the Nyquist frequency), and a cutoff frequency of 0.05 yields a vertical resolution of 20 bins 

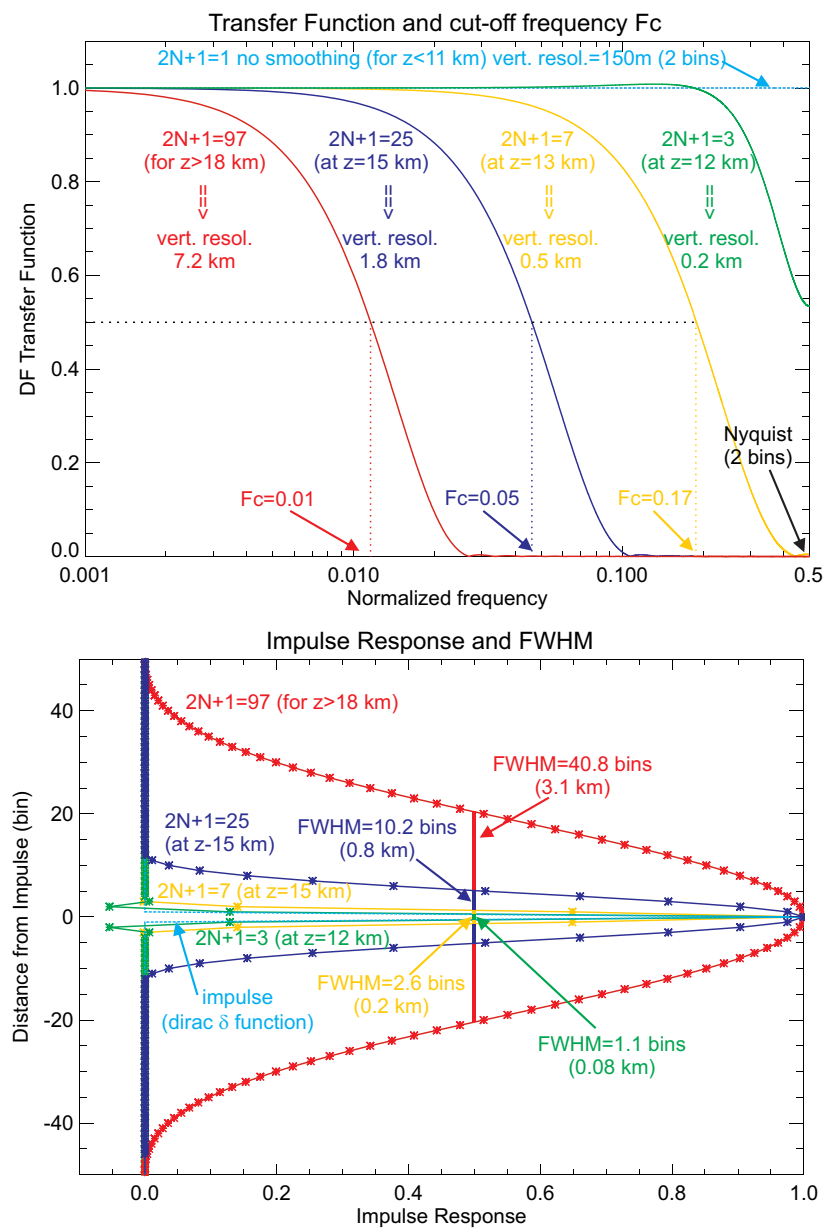

Fig. 2. Effect of the TMW lidar signals vertical filtering based upon two different vertical resolution definitions. Top plot: definition based on the cut-off frequency of a digital filter (Kaiser filter with $50 \mathrm{~dB}$ attenuation). Bottom plot: definition based on the full-width at half-maximum (FWHM) of an Impulse Response to a Dirac Delta Function.

$(1.5 \mathrm{~km})$. The typical variation with height of vertical resolution and the impact of the smoothing on precision is shown in Fig. 3 and Table 1 for a 2-h integrated measurement.

The last stage of the analysis is the calibration of the signal ratios of all 3 pairs of channels, as well as the combination of the pairs into one single profile. This procedure was carefully optimized to insure a minimum impact on the stability of the future lidar long-term time series, and is discussed next.

\subsection{Calibration and profile assembly}

Calibration of water vapor Raman lidar measurements has been extensively discussed in the past (e.g., Vaughan et al., 1988; Sherlock et al., 1999b; Whiteman et al., 2003; Leblanc and McDermid, 2008). There are two main approaches: One approach consists of calculating every single term of Eq. (3) linking $R(z)$ and $q(z)$. Since this task is complex and has

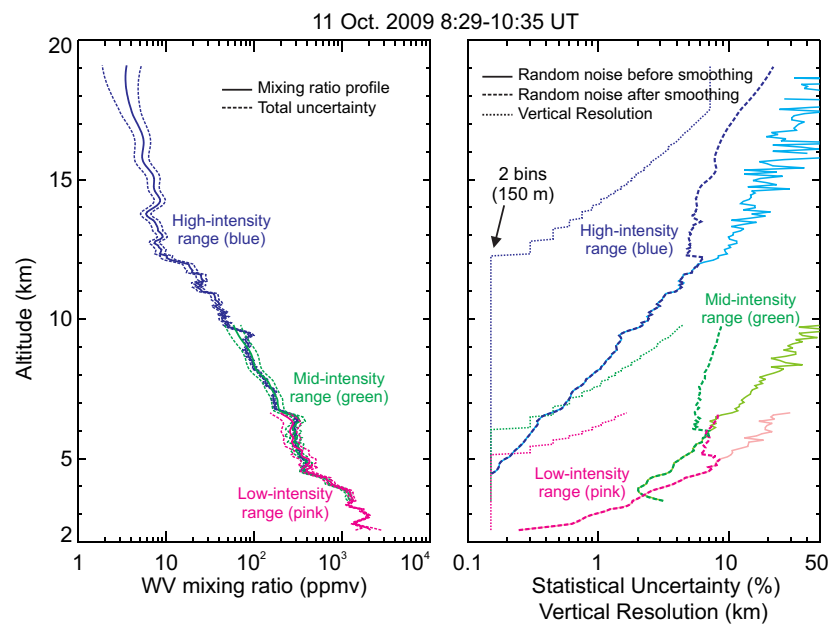

Fig. 3. Example of the effect of vertical filtering on the TMW water vapor profiles. Left plot: mixing ratio profiles for all three ranges (pink: low-intensity, green: mid-intensity, and blue: high-intensity range). Right plot: statistical uncertainty (\%) before (solid curves) and after (dashed curves) filtering, and corresponding vertical resolution $(\mathrm{km})$ (dotted curves) following the definition based on digital filter cutoff frequency.

many sources of uncertainty (including - but not limited to - the accuracy of the lidar parts' manufacturer specifications and the determination of the Raman water vapor crosssection), the resulting calibration overall accuracy using this approach is rarely found to be better than $10 \%$.

A second approach consists of estimating and/or minimizing any height-dependent term in Eq. (3) (namely, the ratio of the overlap functions, differential aerosol extinction, and temperature dependence of the ratio of the Raman water vapor and nitrogen cross-sections), and reduce all the terms of this equation to a single, height-independent proportionality constant. This constant can then be deduced by scaling the lidar ratios to one (or a set of) well-known water vapor mixing ratio value(s) measured by another technique. Radiosonde measurement in the troposphere is the most common source used today. Another common source of calibration is the Total Precipitable Water (TPW) measurement from a co-located GPS or microwave radiometer. When using an external measurement, the accuracy of the calibration procedure follows that of the measurement used. Today the accuracy of the best quality radiosondes, GPS, and microwave measurements is estimated to be $5 \%, 7 \%$ and $10 \%$ respectively (Miloshevich et al., 2009; Gutman, personal communication, 2010; Nedoluha, personal communication, 2011). The accuracy of the lidar calibration using this approach also depends on the quality of the spatio-temporal coincidence between the lidar and the correlative measurement. In the case of the TMW lidar, we carefully evaluated the calibration accuracy using several sources of measurement, several coincidence criteria, and several normalization techniques. The external source 
Table 1. Vertical filtering scheme (Kaiser filter, $50 \mathrm{~dB}$ attenuation) applied to the high-intensity range for a typical 2-h integrated measurement, and resulting vertical resolution and precision.

\begin{tabular}{rrrrrrr}
\hline Alt. & Cutoff & $\begin{array}{r}\text { 2N }+1 \\
(\mathrm{FW})\end{array}$ & $\begin{array}{r}\text { Resol. } \\
(\mathrm{km})\end{array}$ & $\begin{array}{r}\text { I.R.** } \\
(\mathrm{km})\end{array}$ & $\begin{array}{r}\text { Prec. } \\
(\%) \\
\text { before }\end{array}$ & $\begin{array}{r}\text { Prec. } \\
(\%) \\
\text { after }\end{array}$ \\
\hline 4.46 & 0.5 & $1^{*}$ & 0.15 & 0.075 & 0.1 & 0.1 \\
5.06 & 0.5 & $1^{*}$ & 0.15 & 0.075 & 0.2 & 0.2 \\
6.035 & 0.5 & $1^{*}$ & 0.15 & 0.075 & 0.3 & 0.3 \\
7.01 & 0.5 & $1^{*}$ & 0.15 & 0.075 & 0.5 & 0.5 \\
8.06 & 0.5 & $1^{*}$ & 0.15 & 0.075 & 0.9 & 0.9 \\
9.035 & 0.5 & $1^{*}$ & 0.15 & 0.075 & 1.5 & 1.5 \\
10.01 & 0.5 & $1^{*}$ & 0.15 & 0.075 & 2.4 & 2.4 \\
11.06 & 0.5 & $1^{*}$ & 0.15 & 0.075 & 4.0 & 4.0 \\
12.035 & 0.428 & 3 & 0.15 & 0.086 & 6.2 & 6.1 \\
13.01 & 0.173 & 7 & 0.45 & 0.2 & 9.5 & 5.0 \\
14.06 & 0.078 & 13 & 0.9 & 0.4 & 14.8 & 5.9 \\
15.035 & 0.041 & 25 & 1.8 & 0.8 & 22.0 & 7.2 \\
16.01 & 0.023 & 45 & 3.3 & 1.4 & 32.4 & 8.2 \\
17.06 & 0.013 & 77 & 5.7 & 2.4 & 48.3 & 10.7 \\
18.035 & 0.010 & 97 & 7.2 & 3.1 & 69.0 & 15.7 \\
19.01 & 0.010 & 97 & 7.2 & 3.1 & 97.2 & 22.1 \\
20.06 & 0.010 & 97 & 7.2 & 3.1 & $>100$ & 26.0 \\
\hline
\end{tabular}

$* 2 \mathrm{~N}+1=1$ (i.e., $\mathrm{N}=0$ ) means no smoothing. ** I.R. is the filter's corresponding Impulse Response (to Dirac's Delta Function) full-width at half-maximum (FWHM).

consists of Vaisala RS92 water vapor profiles corrected using the method described by Miloshevich et al. (2004, 2009). A combination of the matching and normalization methods producing the least temporal variability (on a yearly basis or longer) was considered the most accurate and was eventually retained for use in the LidAna $\mathrm{v} 7$ standard analysis program. The results of this work are summarized below.

Four different coincidence criteria were tested. Figure 4 shows a schematic of each of the four methods for a 2-h-long lidar measurement. On each figure, the lidar measurements are denoted by red open rectangles symbolizing a series of 24 consecutive 5-min datasets (time-altitude). The external source of calibration (in this case radiosonde) is symbolized by a one-time flight launched at $t=0$ and during which water vapor is measured quasi-instantaneously (blue tilted striped line). The coincidence criterion for each method leads to a set of coincident lidar-radiosonde data pairs used to scale the uncalibrated lidar profile. These data pairs are represented on each figure by the green thick circles. No point above $10 \mathrm{~km}$ altitude is used in the calibration process due to increasing random noise of the lidar signals. For each calibration method the lidar measurements are partially integrated over the time window for which coinciding pairs were found. "Matching Method 1" (top-left) consists of scaling, for each altitude bin, the 2-h lidar average to the instantaneous radiosonde measurement. For "Matching Method 2" (bottomleft), the averaging time window is restricted to the duration of the radiosonde flight below $10 \mathrm{~km}$, which is approximately $30 \mathrm{~min}$. For "Matching Method 3", the entire $2 \mathrm{~h}$ window is used, but only the altitude points where water vapor variability over the 2-h period was less than $20 \%$ are used. Finally, in "Matching Method 4" (bottom-right), only the data points strictly coinciding both in time and altitude are used. For each of the above matching methods, three different scaling algorithms were used. In "Scaling Method 1", a simple average of the ratio calculated for all matching pairs is calculated. For "Scaling Method 2" the mean value is replaced by the median value. In "Scaling Method 3" a Gaussian distribution of the ratios is computed and the calibration constant is set to the center value of this Gaussian function. Eventually 12 cases ( 3 matching methods multiplied by 4 scaling methods) were evaluated.

The standard deviations in the lidar calibration constant obtained from each method over a test-period of 16 months (October 2007-April 2009) are compiled in Table 2, and time series of the calibration constants for six of the twelve cases studied are plotted in Fig. 5. In this figure, the calibration constant is represented by a vertical bar for each of the 118 measurement nights used. First, the uncalibrated lidar ratio for each altitude bin between $3.5 \mathrm{~km}$ and $10 \mathrm{~km}$ is scaled to the radiosonde value. The mean value, median value, or center of Gaussian distribution value is calculated over all available altitude bins. The resulting value is located at the center of the plotted vertical bar. Each bar extends one standard deviation up and down from the mean (for the Gaussian distribution method, it is the full-width at half-maximum). The length of each bar therefore gives an indication of the stability of the calibration process when different altitude 


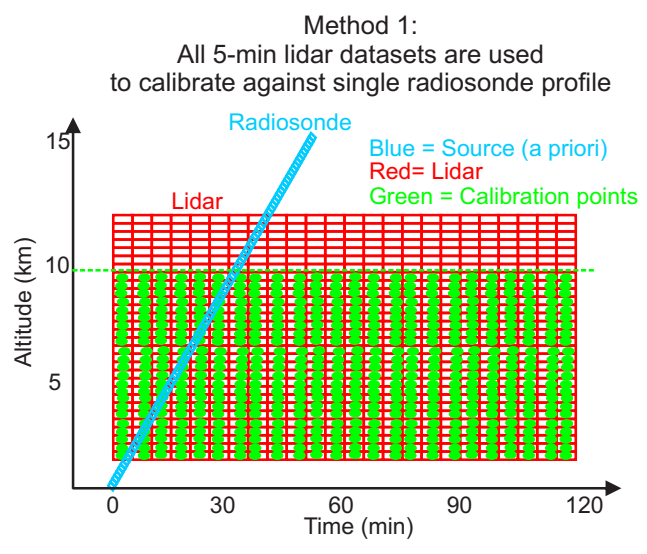

Method 2:

Only time-coincident lidar datasets are used to calibrate against single radiosonde profile

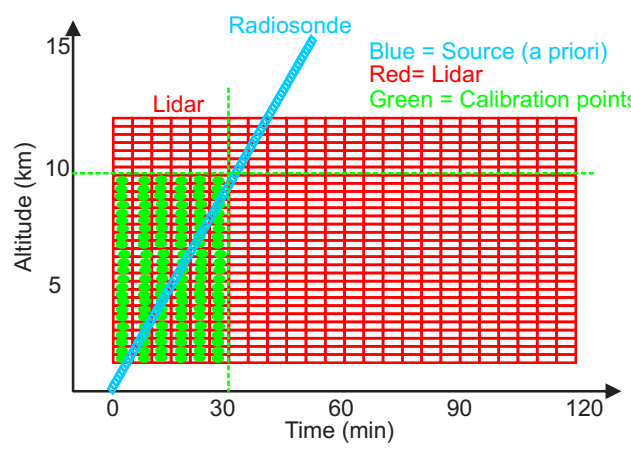

Method 3:

Only altitudes with minimum variability are used

to calibrate against single radiosonde profile

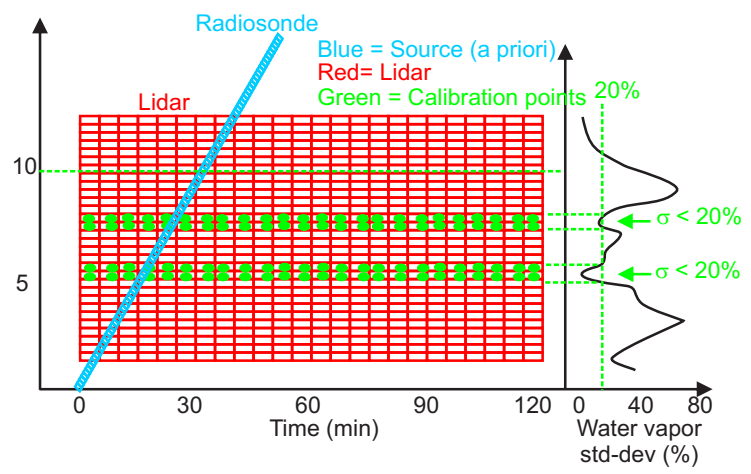

Method 4:

Only time- and altitude-coincident points are used to calibrate against single radiosonde profile

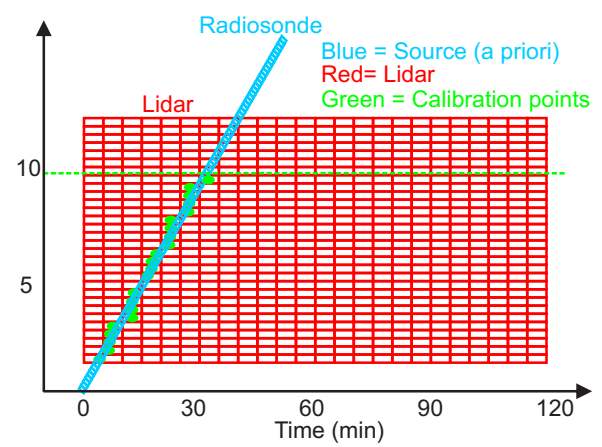

Fig. 4. Schematics of the four methods tested to optimize the calibration of the TMW lidar profiles using co-located radiosondes. Lidar data points are symbolized by red open rectangles, radiosonde data points by small blue open squares tilted with time, and the actual data pairs used for the normalization by filled green circles.

bins are used. However it does not provide an indication of its stability in time. To investigate the stability in time, the standard deviations (in time) of the daily calibration values are computed. Their values are displayed in Fig. 5 as percents of the mean over the period considered. The full time series is divided in 4 uneven periods, indicated by black horizontal bars. The first two periods are short and correspond to the MOHAVE-II campaign (October 2009). They are not used to compute the percentages displayed on the figure. The standard deviations for each of the two other periods, as well as the average of the two, are displayed on the figure. They range from $6.8 \%$ to $14.6 \%$, depending on the method used. Out of all the methods, the "Matching Method 2" (restricted time and unrestricted altitude coincidence) and "Scaling Method 2" (median) turned out to provide the best results. They are now used systematically in our standard data processing. The standard deviation of several other methods remain in the same order of magnitude $(10 \%$ or better), and could therefore be used as well.

In addition to the spatio-temporal match of the lidar and radiosonde profiles, one must pick the best combination of the three ranges (high-intensity, mid-intensity, and low- intensity) in order to insure the best accuracy and stability in time. The profiles from the high-intensity channels contain less random noise at higher altitudes but have a larger uncertainty associated with overlap and saturation at the bottom. On the other hand, the low-intensity channels coupled from the small telescopes are less sensitive to overlap issues at the lowest levels but quickly become noisy above $5 \mathrm{~km}$ altitude. The accuracy degradation of the low- and highintensity ranges is mitigated for the mid-intensity range once corrected for saturation and overlap. We therefore use this range to calibrate the lidar profiles to the radiosonde measurements, typically at altitudes between $4 \mathrm{~km}$ and $7 \mathrm{~km}$. The other two ranges are then normalized to the mid-intensity range using the altitudes of best overlap (typically $6-8 \mathrm{~km}$ for the high-intensity range, and 3-5 km for the low-intensity range). Though we use only one range, calibrating all three ranges independently using the radiosonde profiles yields very similar results in most cases and could be used likewise. An example of profile with all three ranges combined is shown in Fig. 6. 

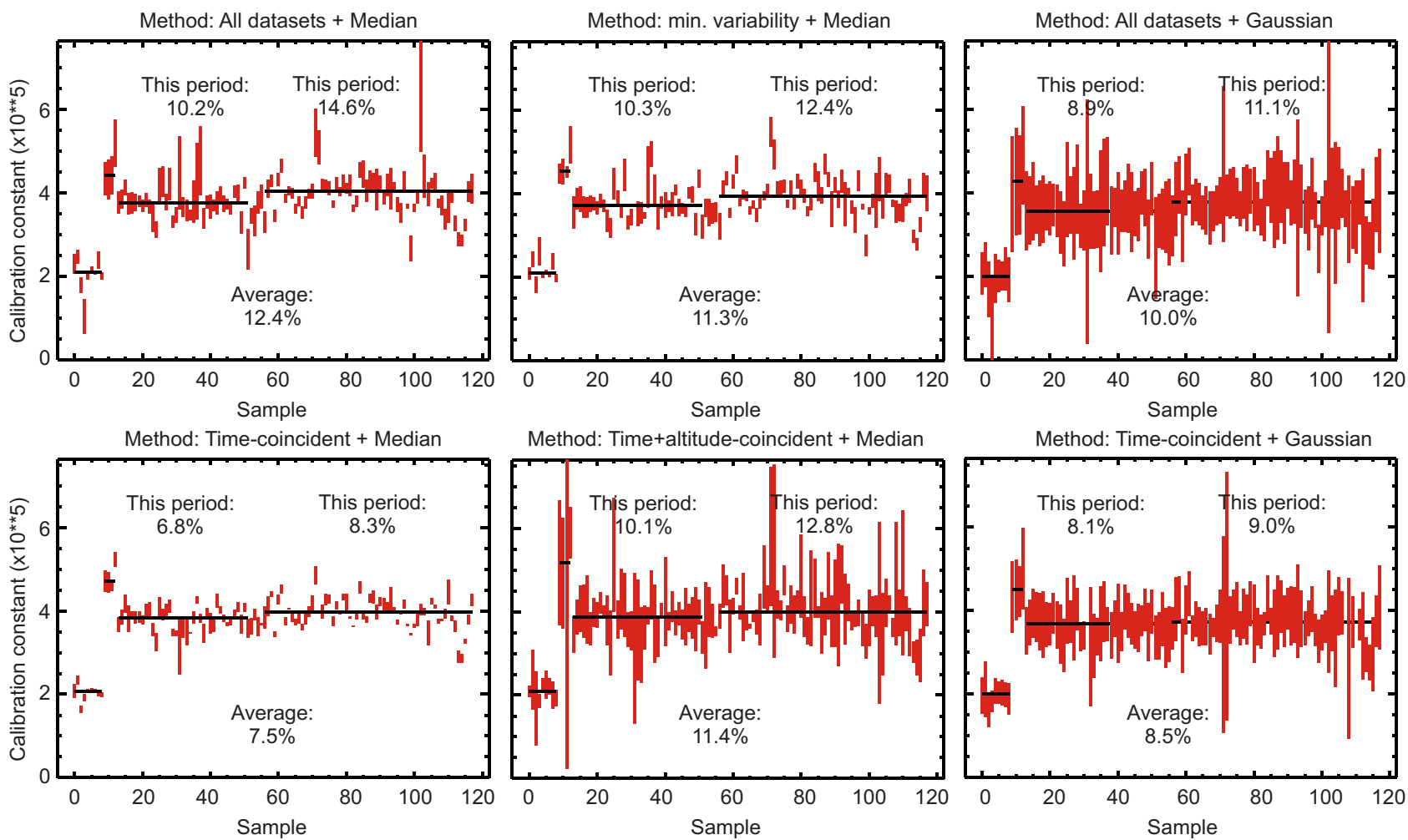

Method: Time+altitude-coincident + Median

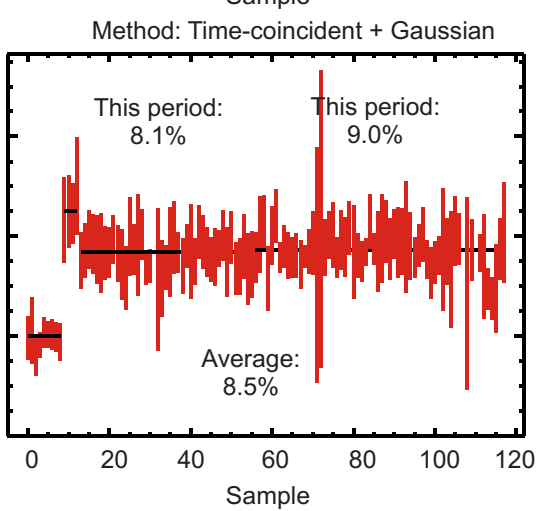

Fig. 5. Six examples of the 12 calibration methods tested. The percentages represent the standard deviations of the calculated calibration constants over 2 sub-periods and averaged over the entire 118 samples (October 2007 to April 2009). See text for details on each method, and Table 2 for a compilation of the standard deviations of all 12 methods.

Table 2. Standard deviation of the lidar calibration constant calculated 120 2-h-long samples over the period October 2007-April 2009 using 12 different calibration methods (single radiosonde coincidences). See text for details.

\begin{tabular}{|c|c|c|c|}
\hline Matching & $\begin{array}{r}\text { Method } 1 \\
\text { (Mean) }\end{array}$ & $\begin{array}{r}\text { Method } 2 \\
\text { (Median) }\end{array}$ & $\begin{array}{r}\text { Method } 3 \\
\text { (Gaussian) }\end{array}$ \\
\hline Method 1 (all datasets) & $16 \%$ & $12 \%$ & $10 \%$ \\
\hline Method 2 (time-coincident) & $8 \%$ & $7 \%$ & $8 \%$ \\
\hline Method 3 (min. variability) & $12 \%$ & $11 \%$ & $10 \%$ \\
\hline Method 4 (time + altitude coincident) & $11 \%$ & $11 \%$ & $11 \%$ \\
\hline
\end{tabular}

\section{Results from the initial configuration (2005-2006)}

The configuration described in Sect. 3.2 was used in 2005 and 2006 up to, and including the first MOHAVE campaign (October 2006). Data were acquired typically during two hours at the beginning of the night and simultaneously with the two other operating lidars on site (tropospheric ozone lidar, and stratospheric ozone/aerosols/temperature lidar). For calibration, the JPL lidar team uses its own Vaisala RS92 radiosonde station. One radiosonde was launched from TMF on each lidar measurement night. Typically the launch time is chosen to coincide with the first hour of the lidar measurement. More than 200 2-h-long lidar profiles were analyzed during the June 2005-October 2006 period. Figure 7 shows the mean water vapor profile obtained simultaneously by the lidar and RS92 radiosondes during this period. Good agreement between the lidar and the radiosonde is found up to about $9-10 \mathrm{~km}$, with an increasing difference is observed as we approach and cross the tropopause, the RS92 being too dry and/or the lidar being too wet. The excessive dryness of the RS92 in the upper troposphere has been known and well documented for many years (Miloshevich et al., 2004, 2009). However, the possible wet bias of the lidar in the UTLS could not be confirmed until the lidar profiles could be compared to accurate measurements in this region. 

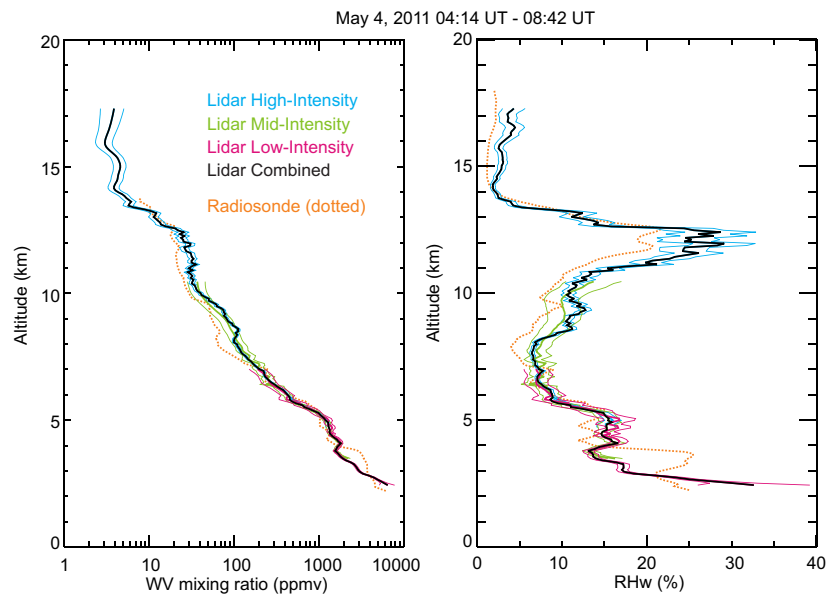

Fig. 6. An example of the construction of the final (black) water vapor (left) and Relative Humidity (right) profiles from the three channel ranges (pink: low-intensity, green: mid-intensity, and blue: high intensity). The lidar profiles total uncertainty is over-plotted using thin solid curves, and a co-located radiosonde profile is over-potted using a dotted orange curve.

These comparisons with accurate measurements took place during the Measurements Of Humidity in the Atmosphere and Validation Experiments (MOHAVE) campaign held in October 2006 with the primary objective of validating the Raman water vapor lidar measurement in the UTLS. Fifty RS92 radiosondes and 10 Cryogenic Frost-point Hygrometers (CFH) (Vömel et al., 2007) were launched from TMF during the 15 nights of the campaign. Two mobile lidars from the Goddard Space Flight Center (GSFC): Aerosol and Temperature Lidar (AT-Lidar) (McGee et al., 1991), and Scanning Raman Lidar (SRL) (Whiteman et al., 2006), were deployed at TMF for the campaign. Each of the three collocated water vapor lidars acquired over $150 \mathrm{~h}$ of measurements ( 2 to $10 \mathrm{~h}$ per night). At least one balloon per night was launched, each payload including one or two RS92. Ten payloads also contained a CFH and an ozonesonde. The lidar data corresponding to the first hour after launch were systematically processed and compared with the balloon measurements. In these 1-h profiles, thin layered structures were well captured by all instruments but the lidar profiles begin to get noisy above $12 \mathrm{~km}$ (Leblanc et al., 2008b). With CFH taken as the reference profile, a dry bias was found in the upper troposphere for the RS92 and a wet bias was found for all three lidars, even though the lidars showed excellent agreement with each other (Leblanc et al., 2008b). After investigating the possible sources of the lidar wet bias and running additional test experiments, signal contamination by fluorescence in the lidar receivers was identified, which led all three lidar teams to modify their instrument configuration. For the JPL lidar, a $355 \mathrm{~nm}$ blocking filter was temporarily installed in front of the fiber optic. The instrument acquired 3 profiles simultaneously with a $\mathrm{CFH}$ in this configuration. The

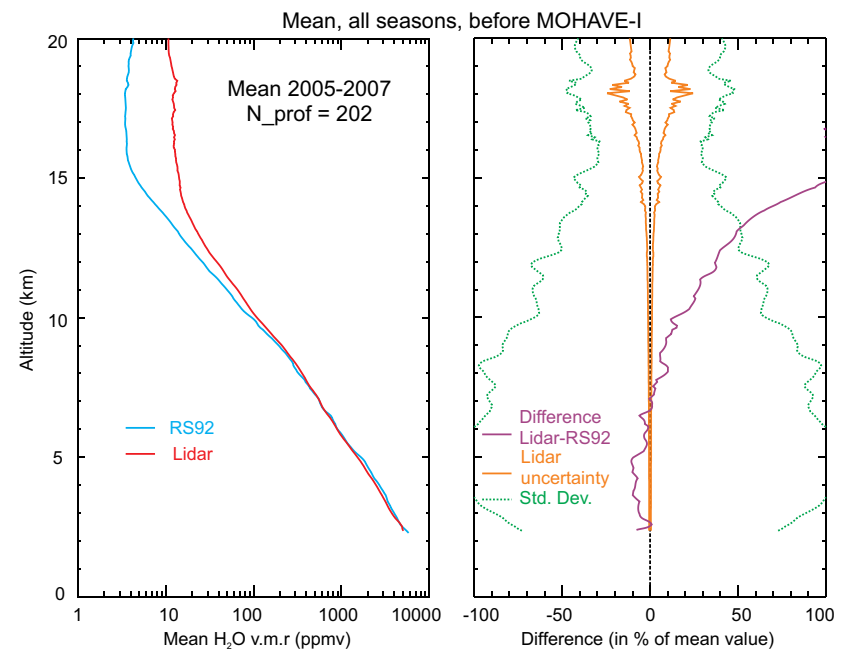

Fig. 7. Comparison of the climatological mixing ratio profiles measured over the period June 2005-October 2007 by the TMW lidar and simultaneous and co-located Vaisala RS92 radiosondes. Left plot: mean profiles. Right plot: mean difference, lidar measurement uncertainty and standard deviation.

difference between the $\mathrm{CFH}$ and lidar profiles during these three flights was compared to that before the modification. The results are plotted in Fig. 8 (left and center plots respectively). As anticipated, the wet bias completely disappeared after the modification (center plot). The nature of the fluorescence contamination was demonstrated by applying a physically-based empirical correction to the contaminated signals. The profiles retrieved from the corrected signals are shown in Fig. 8 (right). The identification and removal of signal contamination by fluorescence was a major milestone in the TMF water vapor lidar project, and a major achievement of the MOHAVE campaign (Leblanc et al., 2008b).

\section{Instrument optimization and validation}

\subsection{Receiver second configuration (2007-2009)}

After MOHAVE, the front-end of the lidar receiver was redesigned to permanently suppress the fluorescence identified in the fiber optic during the campaign. This modification required custom-designed mechanical and optical components and was fully implemented in July 2007. Between MOHAVE and July 2007, only minor modifications were made (including sensitivity tests to fluorescence of several fiber optics). Routine operation continued alternately with and without fluorescence contamination. Signals knowingly acquired with contamination were empirically corrected to remove the effect of the fluorescence. However, because of the added uncertainties, the resulting corrected profiles are flagged and do not contribute to our long-term monitoring program. The modified receiver configuration is shown in Fig. 9 (far-range 

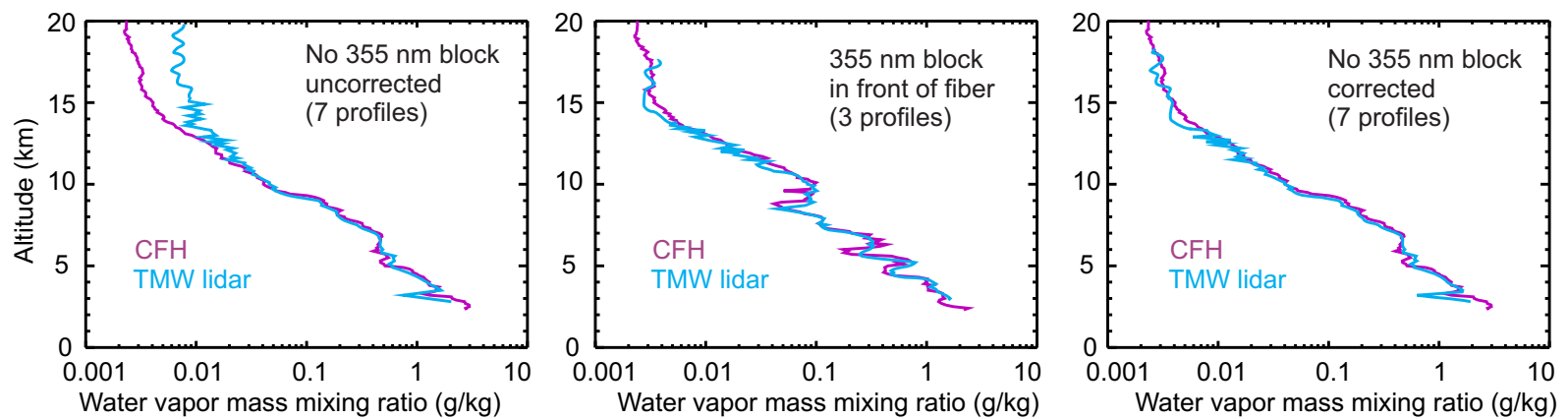

Fig. 8. Comparison of mean water vapor mixing ratio profiles measured simultaneously by the TMW lidar and CFH during MOHAVE-I. Left plot: lidar signals contaminated by fluorescence (no $355 \mathrm{~nm}$ block). Center plot: lidar signals free of fluorescence ( $355 \mathrm{~nm}$ block installed). Right plot: same as left plot, but after fluorescence correction is applied to lidar signals.

channels only) and was fully implemented in July 2007. The strong $355 \mathrm{~nm}$ Rayleigh signal was redirected out of the main optical path ahead of the focus of the large telescope using a long-wave pass beamsplitter (B4) that reflected $355 \mathrm{~nm}$ and transmitted $387 \mathrm{~nm}$ and $407 \mathrm{~nm}$. An additional $355 \mathrm{~nm}$ blocking filter (F4) was placed ahead of the fiber connecting to the polychromator. A separate fiber was used to transmit the $355 \mathrm{~nm}$ to the gated PMT. This arrangement successfully eliminated fluorescence in the $387 \mathrm{~nm}$ and $407 \mathrm{~nm}$ signals (Leblanc et al., 2008b). However, the new and much stronger spectral selectivity resulted in an overall loss of signal by a factor of two, causing a decrease of $3 \mathrm{~km}$ (typically from $17 \mathrm{~km}$ to $14 \mathrm{~km}$ for 1 -h integration) of the uppermost altitude of the instrument.

\subsection{The MOHAVE-II campaign (October 2007)}

To evaluate the effectiveness of the system modifications to remove fluorescence, a second MOHAVE campaign was carried out in October 2007. Again, two mobile lidars from GSFC were deployed for MOHAVE-II. However, the SRL system having sustained major damage during transportation for MOHAVE-I, was replaced by the Atmospheric Laboratory for Validation, Interagency Collaboration, and Education (ALVICE) trailer. ALVICE contains an upgraded version of the Raman Airborne Spectroscopic Lidar (RASL) adapted for ground-based measurements (Whiteman et al., 2007, 2010). The AT lidar had only minor modifications. MOHAVE-II was implemented following operational principles similar to that of MOHAVE-I (Leblanc et al., 2008b). Figure 10 shows the average of the 10 profiles measured simultaneously by all participating instruments and techniques during the campaign. All the lidars agreed well with the $\mathrm{CFH}$ up to $12 \mathrm{~km}$. Though the lidar profiles appear noisier, partly due to the signal decrease mentioned above, no wet bias appears anymore between the JPL lidar (magenta curve) and the $\mathrm{CFH}$ (green). On average, a 1-h lidar integration reached $\sim 15-16 \mathrm{~km}$ for the JPL system. A dry bias was still present on the uncorrected RS92 profile (red). This figure shows

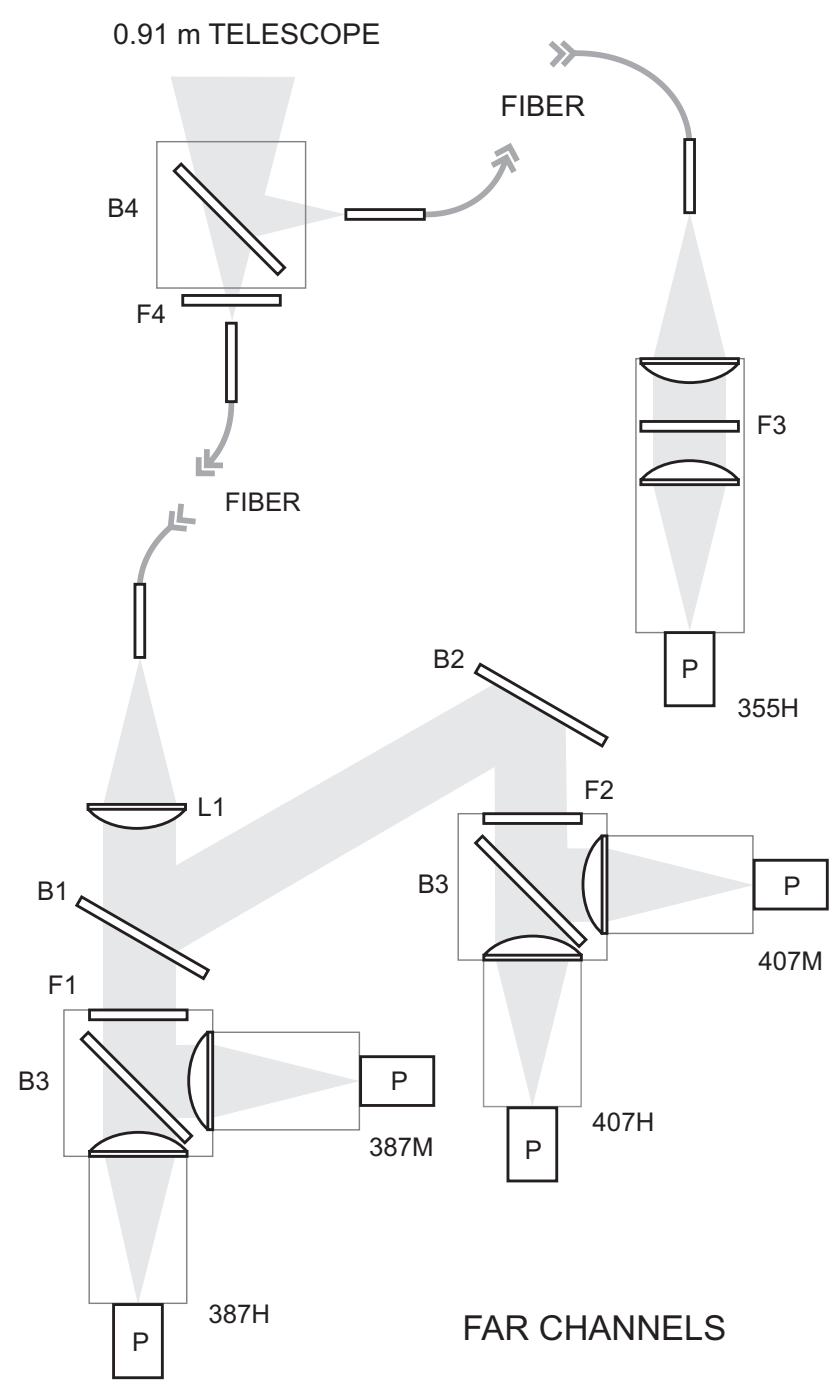

Fig. 9. TMW lidar receiver second configuration (2007-2009) for the high- and mid-intensity channels. 


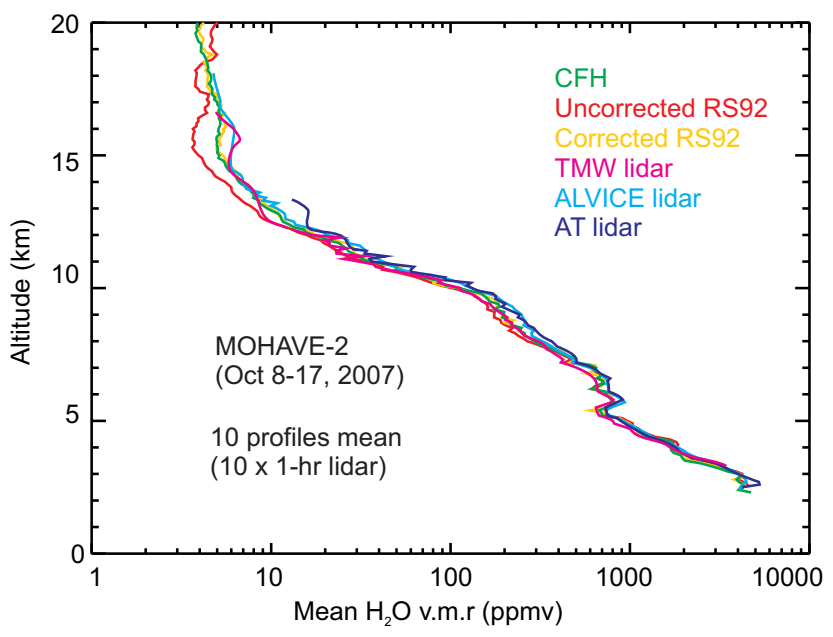

Fig. 10. Averaged water vapor mixing ratio computed from 10 profiles measured simultaneously during MOHAVE-II by the TMW lidar, two other lidars, CFH, and Vaisala RS92 radiosondes.

that the measurement accuracy of the Raman lidar is better than that of the RS92 in the UTLS. The CFH measurement remains the best quality among all instruments but its cost per profile is much higher ( $>\$ 3000$ per $\mathrm{CFH}$ launch) than that of the lidar and clearly prohibitive for long-term, routine monitoring, i.e., multiple measurements per week.

\subsection{Receiver current configuration (2009-present)}

While the installation of the additional optics to divert the $355 \mathrm{~nm}$ returns into a separate fiber eliminated the fluorescence contamination and brought the lidar profiles into agreement with the $\mathrm{CFH}$, the signal levels, and consequently the altitude range of the measurement were reduced. Simulation of the expected lidar returns and comparison with other systems suggested that significant signal was being lost somewhere in our receiver; most likely coupling in and out of the fibers. To try to recover the signal level and potentially increase it, it was decided to eliminate the fibers completely and to reposition the receiver at the telescope Newtonian focus.

Figure 11 is a schematic of the current receiver configuration (far-range channels only). To make the system more compact a new $387 / 407 \mathrm{~nm}$ beamsplitter (B1') operating at $45^{\circ}$ angle of incidence was acquired to replace the previous one that operated at $30^{\circ}$. All of the other optical components were the same as described previously except for the field stops (FS). The new field stops were calibrated, ringactivated iris diaphragms that enabled the field-of-view to be varied as opposed to the fixed fov defined by the fiber diameter in the earlier configurations. This flexibility provided better optimization of laser/telescope overlap and sky background rejection. Values of $600 \mu \mathrm{rad}$ and $800 \mu \mathrm{rad}$ were finally selected for the Raman and $355 \mathrm{H}$ channels respectively.

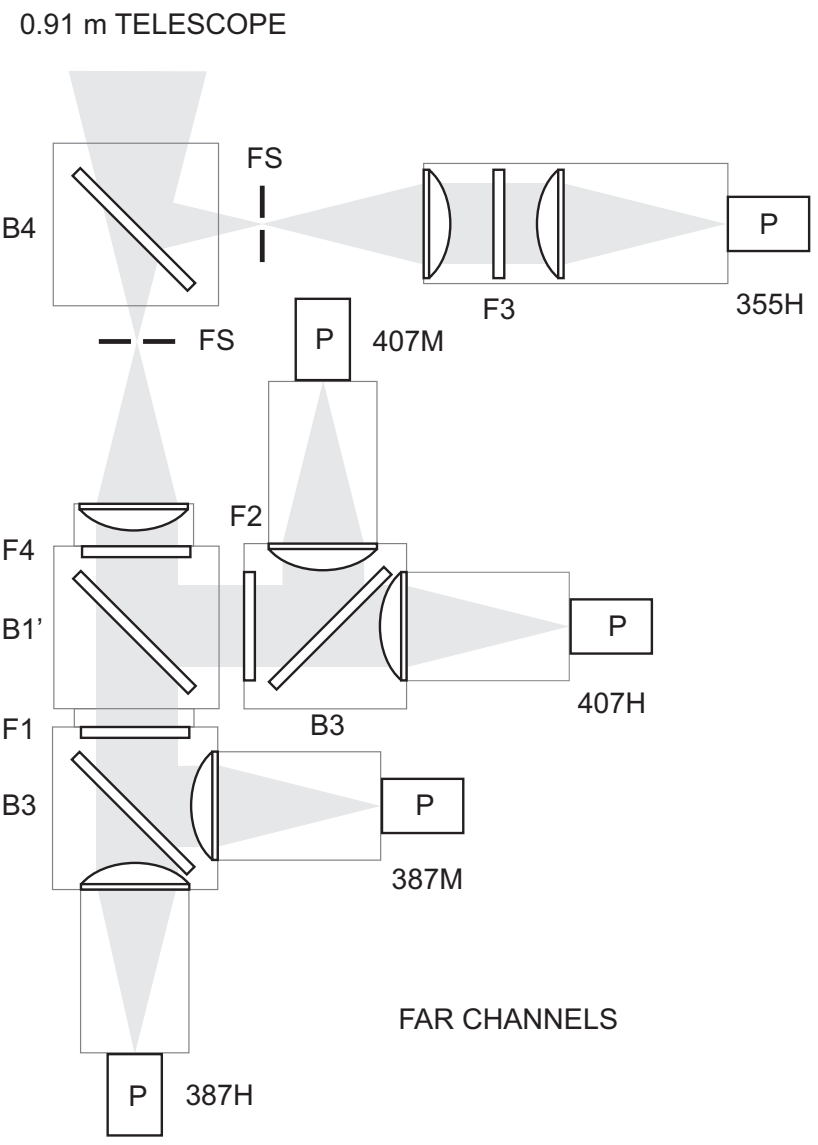

Fig. 11. TMW lidar receiver final configuration (2009-present) for the high- and mid-intensity channels.

The various components of the receiver were aligned on top of each other to minimize obscuration of the large telescope and a calibration lamp was permanently mounted to the side of the receiver module. The purpose of this lamp is discussed in Sect. 8.2.

One other change in this final configuration was to the $407 \mathrm{H}$ photomultiplier detector. The original Hamamatsu H5783P module was replaced with a H10682-110 photon counting head device. Within this module, the PMT high voltage supply and discriminator level are factory preset to optimum values. Also, the PMT in this device has a super-bialkali (SBA) photocathode which has higher quantum efficiency than standard PMTs; $33 \%$ at $407 \mathrm{~nm}$ compared to $25 \%$ (eventually, when commercially available, ultra-biakali (UBA) photocathodes will further raise the QE to $\sim 40 \%$ ). The net result of all these changes was an order of magnitude increase in signal levels. However, such major changes required re-evaluation/validation and therefore another campaign, MOHAVE-2009 was organized. 

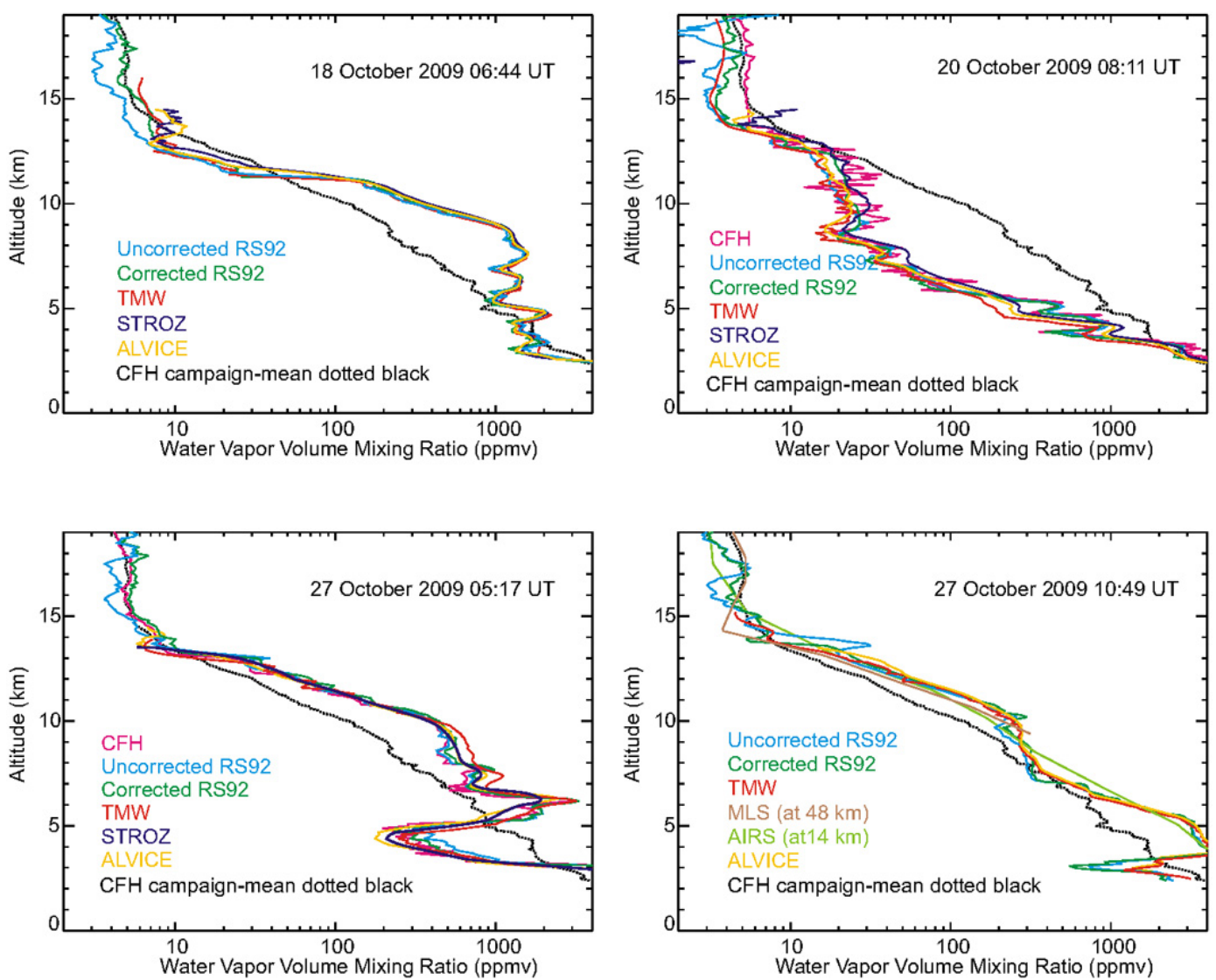

Fig. 12. Example of four water vapor mixing ratio profiles measured simultaneously by TMW, two other lidars, CFH, Aura-MLS, and RS92 radiosondes during MOHAVE-2009.

\section{The MOHAVE-2009 campaign (October 2009)}

The modifications described above occurred in the summer of 2009 (July, August and September). No further changes occurred after that and the instrument remained untouched throughout the MOHAVE-2009 campaign with the exception of the calibration lamp, which purpose is described in the next section. This third MOHAVE campaign was by far the largest of all three MOHAVE campaigns with many participating instruments: two types of frost-point hygrometers (CFH and NOAA-Frost Point), two types of radiosonde (Vaisala and InterMet), two microwave radiometers (NRL and University of Bern), two FourierTransform spectrometers (the JPL MkIV and FTUVS), and two GPS receivers participated in the campaign. Coincident measurements from several satellite instruments (AuraMLS, Aqua-AIRS, Aura-TES, ENVISAT-MIPAS and ACEFTS) were also compared to the balloon-borne and groundbased measurements. The campaign lasted for approximately two weeks between 11 October and 27 October 2009. A overview of the campaign operations and results is presented in Leblanc et al. (2011). Documentation and selected results can be found on the campaign website: http: //tmf-lidar.jpl.nasa.gov/campaigns/mohave2009.htm. A total of 44 balloons were launched. Each balloon payload contained a minimum of one single radiosonde and a maximum of two radiosondes, one ozonesonde, and one hygrometer sonde. A total of $58 \mathrm{RS} 92$ radiosondes, $16 \mathrm{CFH}, 4$ NOAA$\mathrm{FPH}$, and $16 \mathrm{ECC}$ ozonesondes were launched over the duration of campaign. Approximately $300 \mathrm{~h}$ of water vapor lidar measurements were acquired. Results from MIPAS, the MkIV spectrometer, balloon measurements, and two lidar instruments are presented in Stiller et al. (2011), Toon et al. (2011), Hurst et al. (2011b), Whiteman et al. (2011), and McGee et al. (2011), respectively.

Water vapor has different scales of natural variability in the troposphere and stratosphere (see for example Fig. 8 of Leblanc et al., 2011). For this reason the coincidence criteria used for the comparisons presented here are different above and below $14 \mathrm{~km}$ : all profiles coinciding within $1 \mathrm{~h}$ and $100 \mathrm{~km}$ were used for altitudes below $14 \mathrm{~km}$, and all profiles coinciding within $6 \mathrm{~h}$ and $250 \mathrm{~km}$ were used for all altitudes above $14 \mathrm{~km}$.

Figure 12 shows four examples of water vapor profiles measured simultaneously during the campaign. In all plots, the lidar profiles (TMW, ALVICE and STROZ) were 

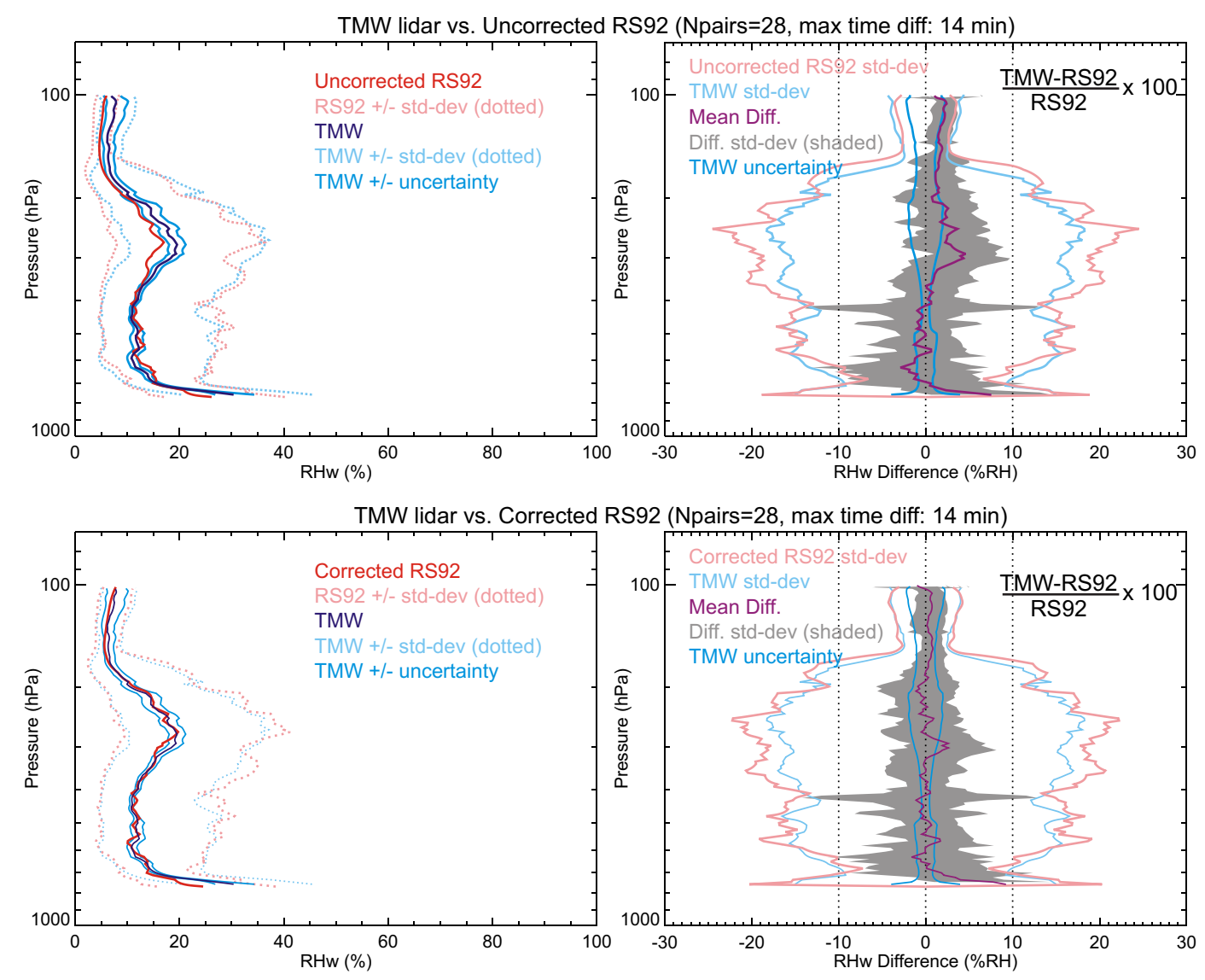

Fig. 13. Comparison of the MOHAVE-2009 campaign-averaged relative humidity profiles calculated from the 28 simultaneous profiles measured by the TMW lidar and Vaisala RS92 radiosondes. Top plots: mean profiles (left) and difference with the uncorrected RS92 data (right). Bottom plots: mean profiles (left) and difference with the corrected (Miloshevich et al., 2004; 2009) RS92 data (right).

obtained from a 1-h integration starting at the corresponding balloon launch time. The CFH campaign-mean profile is provided on each plot for reference purposes only. 18 and 20 October (top-left and top-right) illustrate the very large natural variability in the troposphere from one night to another: very humid upper troposphere on 18 October and very dry on 20 October. Most of the very fine vertical structures (sometimes less than 1-km deep) are well captured by all balloonborne and lidar instruments. A well-known RS92 dry bias is again systematically observed above $12 \mathrm{~km}$ (cyan curves). The RS92 profiles corrected following the method described by Miloshevich et al. (2009) show a better agreement with lidar and CFH above $13 \mathrm{~km}$. The difference between corrected and uncorrected profiles can reach $35 \%$ and is reviewed in Leblanc et al. (2011). The bottom-left and bottom-right plots of Fig. 12 show profiles measured on the night 27 October. Besides showing very large vertical changes (from $200 \mathrm{ppmv}$ to $2000 \mathrm{ppmv}$ in less than $2 \mathrm{~km}$ ), the two figures illustrate the very high temporal variability on short timescales, namely a change at $4 \mathrm{~km}$ altitude from $200 \mathrm{ppmv}$ to $4000 \mathrm{ppmv}$ in a $5-\mathrm{h}$ interval. The very fine and fast-changing structures observed on all plots of Fig. 12 confirm the need for extra care when producing comparisons between the various instruments and techniques.

Figure 13 shows the campaign average of all TMW and all RS92 relative humidity ( $\mathrm{RH})$ profiles measured simultaneously (i.e., within 1-h of balloon launch), and their mean difference. The comparisons are shown for the RS92 uncorrected (top row) and corrected (bottom row) versions. As mentioned before, the TMW profiles were calibrated using the radiosonde profiles between 4 and $7 \mathrm{~km}$. The corrected version of the RS92 profiles was used, leading obviously to a near-zero difference in the resulting $\mathrm{RH}$ over the pressure range $600-400 \mathrm{hPa}$ (Fig. 5, bottom-right). At these pressures, a small negative bias with the uncorrected RH is observed, a direct consequence of the effect of the RS92 correction (corrected RH values smaller than uncorrected values). Most interestingly, the mean bias between the lidar and the corrected RH remains almost negligible (below 3\%) and not statistically significant all the way up to $100 \mathrm{hPa}$. In the upper troposphere, a mean bias of 3-5\% is observed, the radiosonde being drier than the lidar.

Figure 14 (top row) shows the campaign average of all coincident water vapor profiles (left) measured by TMW and 

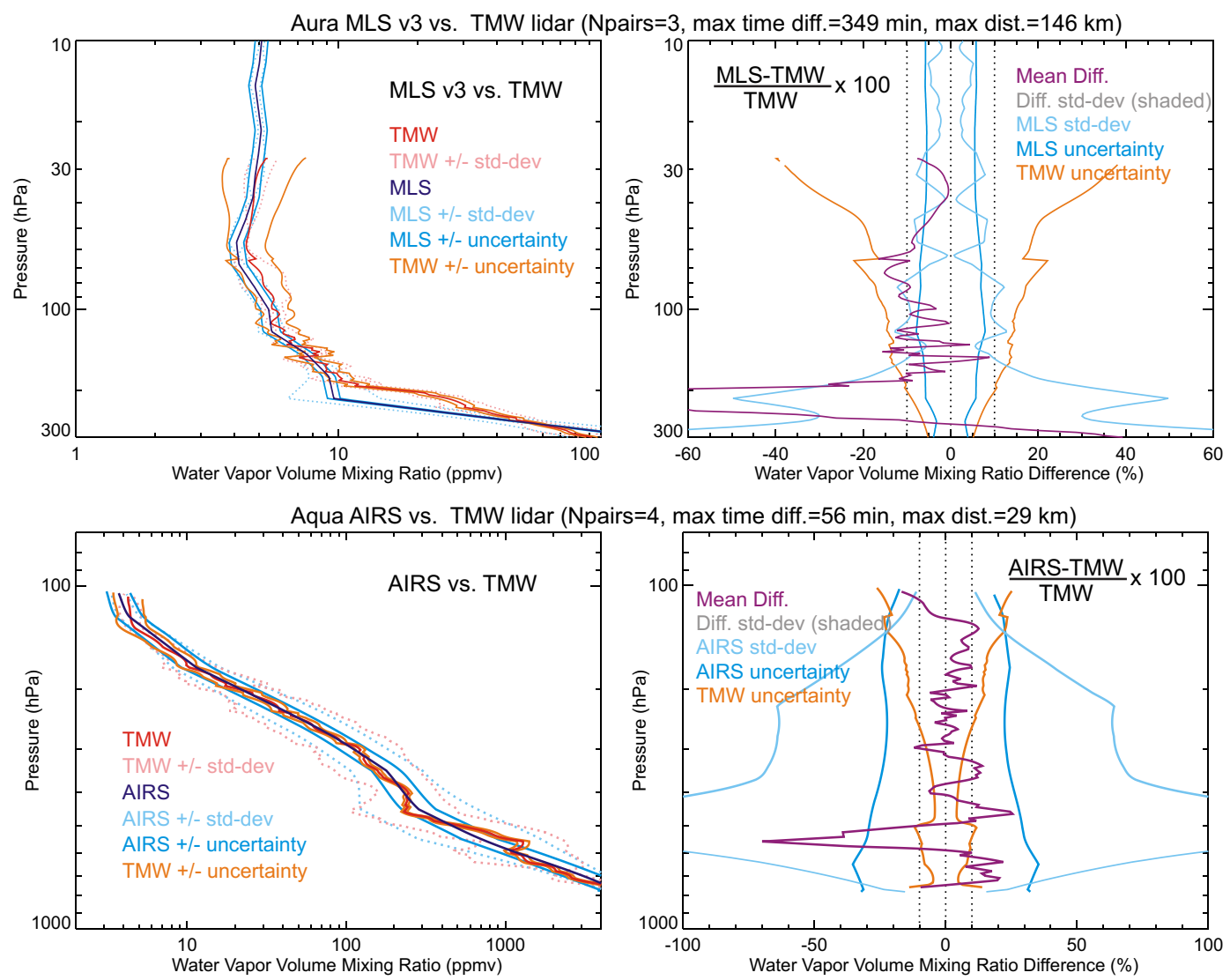

Fig. 14. Top: averaged mixing ratio profiles (left) calculated from the 3 coincident profiles measured in the UTLS by the TMW lidar and Aura-MLS during MOHAVE-2009, and their difference (right). Bottom: averaged mixing ratio profiles (left) calculated from the 4 simultaneous profiles measured by the TMW lidar and Aqua-AIRS during MOHAVE-2009, and their difference (right).

Aura MLS (version 3), and their difference (right). As we are in the UTLS, the coincidence criterion was relaxed from that in the troposphere. Nevertheless, only 3 profiles were found coincident. MLS shows a 7-10\% dry bias in the lower stratosphere (200-30 hPa) with respect to TMW. However the bias is not statistically significant. The only significant difference is a large dry bias for MLS at $250 \mathrm{hPa}$. This feature is caused by the retrieval in response of the very fast transition from the dry stratosphere to the wet troposphere. The bottom row of Fig. 14 shows the campaign average of all coincident water vapor profiles (left) measured by TMW and Aqua-AIRS, and their difference (right). Despite the very different sampling type, the two instruments remain in very good agreement. A $5 \%$ bias can be observed (AIRS being wetter) between $400 \mathrm{hPa}$ and $150 \mathrm{hPa}$. Below $400 \mathrm{hPa}$ the somewhat larger differences are not statistically significant.

Finally the campaign-mean profiles measured simultaneously by the TMW lidar and CFH, and their difference, are plotted in Fig. 15 as a function of pressure (a-d), and as a function of geometric altitude (e-f). Since the CFH is the most accurate instrument in the UTLS participating to the MOHAVE-2009 campaign, this figure is indeed the most important result of the campaign for the TMW lidar and it summarizes well the performance achieved by the TMW lidar since MOHAVE-2009. Geopotential height is computed from the simultaneous RS92 pressure and temperature data, and then converted to geometric height. Below $14 \mathrm{~km}$ (approx. $100 \mathrm{hPa}$ ), only the strictly coincident profiles were used to compute the mean (i.e., $12 \mathrm{CFH}$ flights and the 12 corresponding 1-h integrated lidar profiles). Using the 1-h integrated profiles prevents the lidar reaching altitudes above $14 \mathrm{~km}$. In the UTLS, the lidar profiles integrated all-night were used (mean of 8 nights during which $9 \mathrm{CFH}$ were launched). The TMW lidar and CFH profiles are in excellent agreement throughout the troposphere and the UTLS. The mean differences range from $-5 \%$ in the lowermost troposphere (TMW drier) to $+2 \%$ in the lower stratosphere (TMW wetter). These values are well below the reported uncertainties of both instruments

A close look at the top-left plot of Fig. 15 (UTLS, 15$20 \mathrm{~km}$ or $200-50 \mathrm{hPa}$ ) reveals that the standard deviation of the lidar measurements above $17 \mathrm{~km}$ (approx. $100 \mathrm{hPa}$ ) is two to three times larger than that of the CFH. This number provides a good indication of the number of additional lidar measurements needed to achieve the same precision as CFH. With the assumption that lidar data contains random noise 

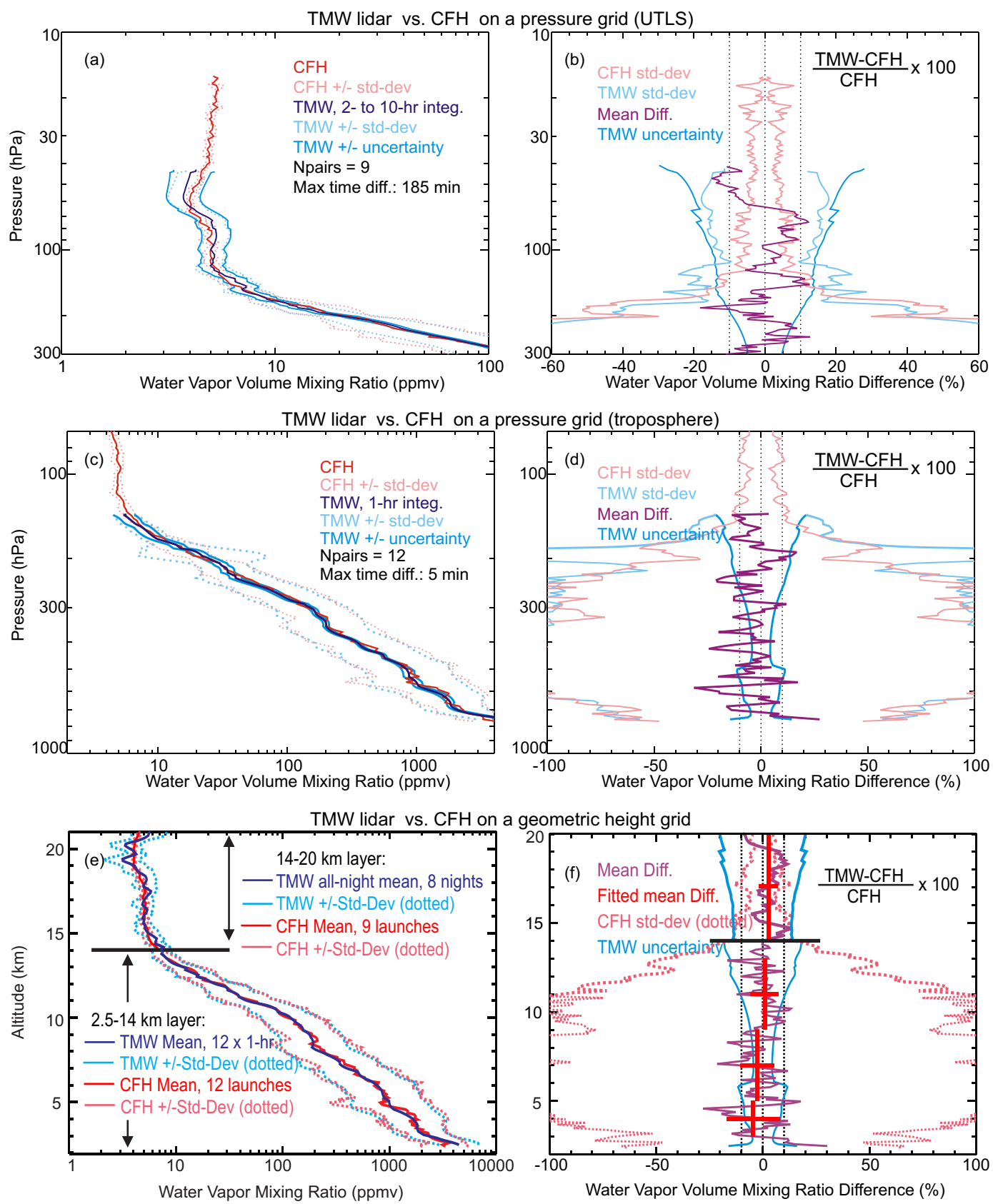

Fig. 15. Comparison of the MOHAVE-2009 campaign-averaged mixing ratio profiles (left) calculated from all coincident profiles measured by the TMW lidar and the CFH, and their difference (right). Top row (a-b): UTLS on a pressure grid; middle row (c-d): troposphere on a pressure grid; bottom row (e-f): troposphere and lower stratosphere on a geometric height grid. See text and figure for details on the coincidence criteria.

following a Poisson distribution, using one to two CFH profiles yields a precision in the UTLS equivalent to integrating the lidar measurements for 5 to 8 full nights (i.e., 40 to $70 \mathrm{~h}$ ). That is, one weekly CFH launch yields a precision in the UTLS similar to that of the integrated lidar measurement of 4 full nights per week. Similarly, one monthly CFH profile yields a precision in the UTLS equivalent to that of the inte- grated lidar measurement of one full night per week, or four 2-h-long measurements per week. These estimations therefore show that, with our current target to run TMW for two hours per night, 4 nights per week, we can achieve a precision in the UTLS equivalent to that achieved when launching one $\mathrm{CFH}$ per month 


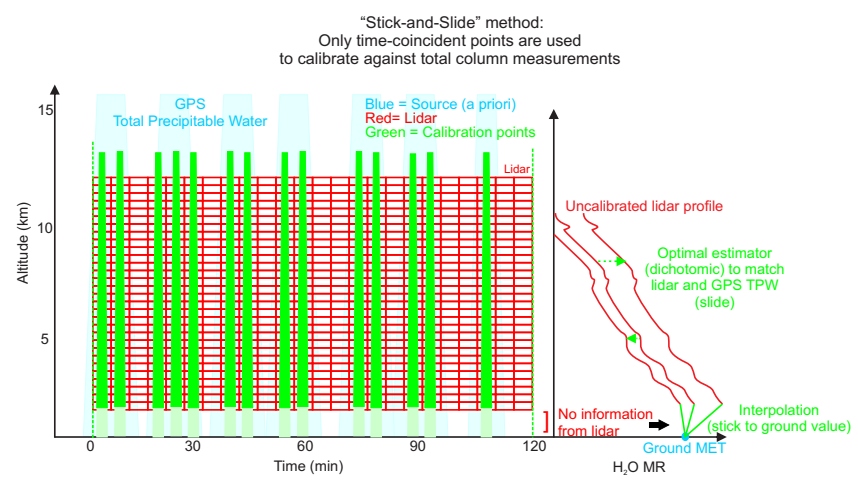

Fig. 16. Schematics of the "stick-and-slide" method used to perform a calibration of the TMW lidar profiles using co-located and simultaneous GPS Total Precipitable Water measurements. Lidar data points are symbolized by red open rectangles, GPS column data by blue vertical bars, and the actual column data pairs used for the normalization by filled green vertical bars. The sliding uncalibrated lidar profile is shown in red, the constrained water vapor ground-measurement in blue, and the "sticky" interpolated layer in green. See text for details.

\section{Additional considerations for long-term monitoring}

\subsection{Alternative calibration using Total Precipitable Water (TPW)}

In order to ensure the proper long-term monitoring of water vapor mixing ratio, the calibration must remain as stable as possible on large time scales (several years). Therefore, an alternative source of external measurement for the calibration of TMW is now systematically used, namely the TPW measurements from a co-located GPS (Whiteman et al., 2006). Since the lidar cannot sample all altitudes down to the ground, the scaling of total water must be made carefully and the lidar-blind lowest atmospheric layers must be taken into account. To achieve this, the lidar profiles are extrapolated down to the ground using surface measurements obtained every $5 \mathrm{~min}$ from a co-located Vaisala Weather Station (MAWS-1). The scaling process is illustrated in Fig. 16 with the same coloring conventions as Fig. 4 (i.e., red for lidar, blue for external source, and green for coincident data pairs). Note that the GPS measurements are sampled every 15 -min, which corresponds to using 3 correlative 5 -min lidar datasets. The schematic on the right side of the figure illustrates the scaling method, referred to as "Stick-andSlide": the uncalibrated lidar mixing ratio profile is glued to the ground ("stick") using the surface measurements by the Vaisala MAWS. The contribution from the lowermost layers is taken into account by interpolating the mixing ratio between the ground value and the uncalibrated lidar profile bottom value. The uncalibrated profile is shifted ("slide") until the corresponding TPW exceeds or falls below the value measured by the collocated GPS. For each sliding in- terval, the contribution of the lowermost layers must be reinterpolated. The lidar-computed TPW converges to the GPS value by reversing the sliding direction multiple times and by dividing the sliding interval by two each time a change of direction occurs. The algorithm stops when the difference between the lidar-computed and GPS-measured TPW values falls below a user-specified residual (for example $0.1 \%$ ). Sensitivity tests have shown that the method is most efficient when the uncalibrated lidar profile is cut-off at a bottom altitude where a compromise is reached between the impact of signal saturation and/or overlap and the impact of missing measurements between the ground and the first useful lidar sampling bin. In particular, it is more accurate to cut-off the lidar profile a few hundred meters farther up and avoid any profile segment contaminated by saturation or overlap, than starting the profile in its lowermost sampling bins where contamination may have occurred. Assuming no contamination by saturation or overlap, the accuracy of the "Stick-and-Slide" method was found to be around $5 \%$ when the (contamination-free) lidar profile is cut-off $500 \mathrm{~m}$ above ground, and $15 \%$ when it is cut-off $1000 \mathrm{~m}$ above ground. This degradation follows from the accumulated uncertainty associated with unaccounted water vapor in the lowermost layers. Additional uncertainty comes from the inherent accuracy of the GPS (or microwave) measurements, i.e., $7 \%$ or $10 \%$. Overall this calibration method is a good alternate to the radiosonde calibration method, though not as accurate. However, it has potentially the advantage of being more stable over longer periods of time (several years), because it is not subject to manufacturer changes like those experienced over the past few decades with radiosonde (several Vaisala radiosonde versions, each having different observed biases).

\subsection{Hybrid calibration}

The requirement for long-term stability of the lidar calibration has been mentioned several times in this paper already. Indeed even after the calibration method was optimized for our TMW lidar, natural variability of tropospheric water vapor can lead to calibration changes of $15 \%$ or larger from night to night, which does not reflect the actual changes of the lidar system but simply the fact that a different region of the atmosphere was sampled by lidar and radiosonde. The only solution to this problem is to launch not one, but several radiosondes during the same lidar experiment (typically four radiosondes for a 2-h long lidar experiment). Though radiosondes are affordable such an intensive launch plan is too expensive and therefore not cost effective to the routine, long-term measurements of water vapor by lidar. However, and as explained below, a well chosen combination of radiosonde and partial calibration experiments can bring a solution to the problem.

Since 2007, we have systematically used a calibration lamp to monitor the changes in the calibration of the lidar receiver. The lamp is currently mounted on the receiver 

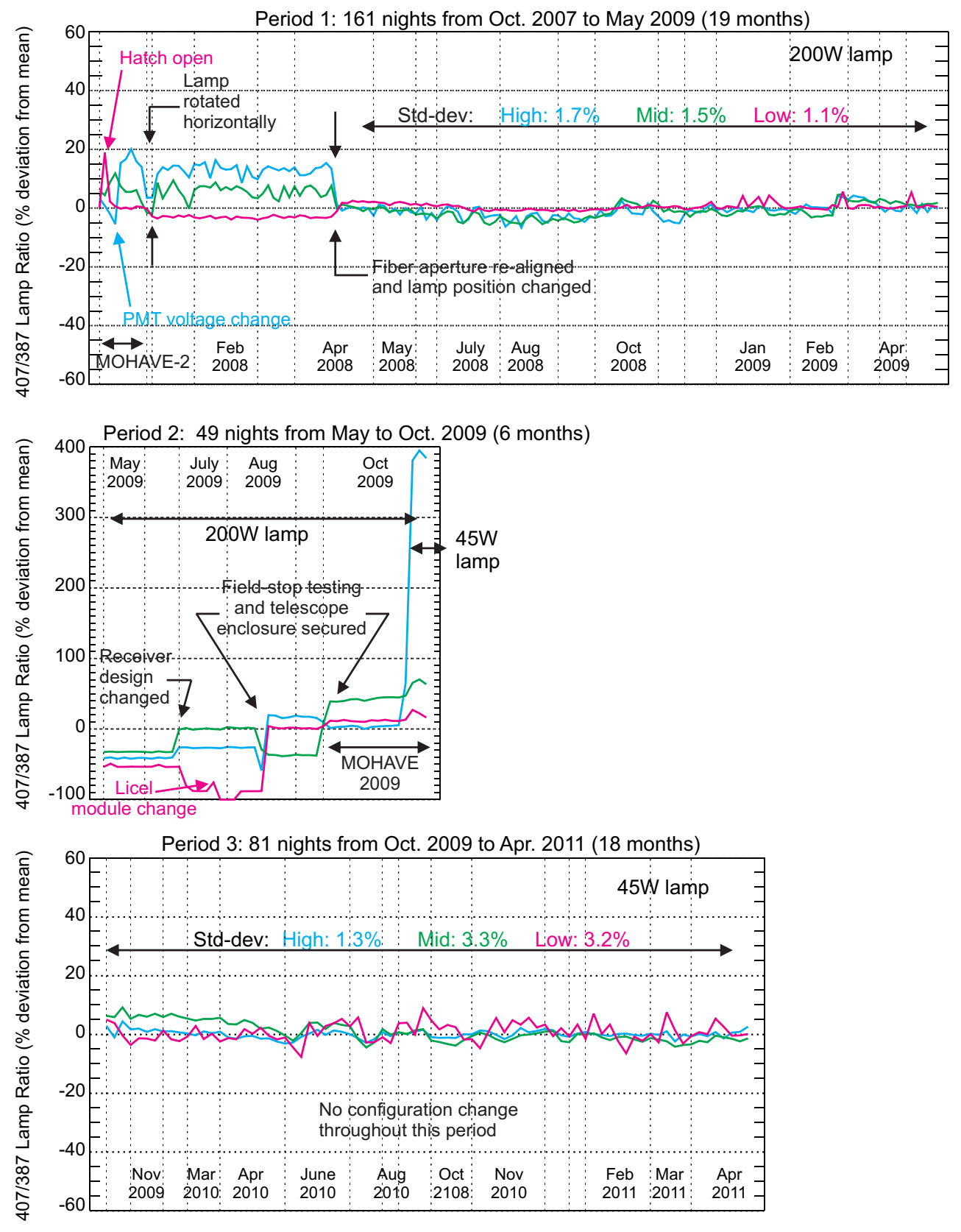

Fig. 17. Historical evolution of the $407 \mathrm{~nm}$ to $387 \mathrm{~nm}$ channel ratios (pink: low-intensity, green: mid-intensity, and blue: high-intensity) between October 2007 and present. All instrumentation changes are denoted by arrows and comments, including the change of lamp (from $200 \mathrm{~W}$ to $45 \mathrm{~W}$ ) in October 2009.

module next the large telescope Newtonian focus and illuminates mostly downward towards the primary mirror and partially upward towards the roof hatch. Following the method described by Leblanc and McDermid (2008), signals coming from the illumination of the lamp with the hatch closed and with the laser turned off are acquired for $15 \mathrm{~min}$ before and after a regular atmospheric water vapor data acquisition experiment. The $387 / 407 \mathrm{~nm}$ ratio obtained during these routine "lamp-runs" is used to monitor any changes in the receiver transmittance, then compared to that obtained during occasional, intensive calibration campaigns (typically once a year). If this ratio has not changed significantly, then an absolute calibration can be applied retrospectively to all experiments acquired between the two campaigns. This procedure allows saving time and money since routine radiosonde launches are no longer required. It also potentially reduces uncertainty associated with spatio-temporal matching since the calibration constant can be averaged using many launches 
made during a campaign instead of relying on individual coincidences. Another advantage is the flexibility to choose only the most stable nights, variability-wise, during which absolute calibration is performed. A critical requirement for the Hybrid method to be valid is that the lamp must remain fixed at the same location and undisturbed throughout the period between two consecutive campaigns. If the lamp is moved, or if any change in the partial calibration constant is detected between absolute calibration campaigns, then radiosondes must be launched immediately to quantify the impact of these changes on the absolute calibration constant. The Hybrid method is described in details in Leblanc and McDermid (2008). Though radiosondes are used in the hybrid method described here, any source of accurate measurement may be used for the absolute calibration campaigns.

Two lamps ( $200 \mathrm{~W}$ and $45 \mathrm{~W}$ Quartz-Tungsten Halogen) have been used since the hybrid method was introduced in October 2007. A complete review of the signal ratios of the 387 and $407 \mathrm{~nm}$ channels obtained during the routine lamp runs is presented in Fig. 17. Three periods are presented, which corresponds to the different receiver configurations already discussed. The top figure shows the signal ratios for all three ranges (high-, mid- and low-intensity) between October 2007 (MOHAVE-II, when the lamp runs started) and summer 2009. This figure is indeed an extension of Fig. 8 of Leblanc and McDermid (2008), in which the observed jumps and drops in the channel ratios until April 2008 are discussed. These features will not be discussed again here, though the instrumentation changes are noted on the figure. The second plot (middle) highlights the major configuration changes made between June and October 2009: receiver redesign, field stop optimization, and most importantly, lamp change (from $200 \mathrm{~W}$ to $45 \mathrm{~W}$ ) during MOHAVE-2009. The third period (bottom plot), extending from MOHAVE-2009 to present time, shows the channel ratios since the $45 \mathrm{~W}$ lamp has been in operation. No instrumentation change was made throughout this period. Inspection of all three plots leads to several important conclusions. First, and as anticipated in Leblanc and McDermid (2008), the channel ratios obtained during lamp runs remain very stable over time (standard deviation mostly below $1.5 \%$ over timescales of a year) unless an instrumentation change occurs. Second, no apparent drift is observed at these timescales with the exception of the midrange channel ratio during period 3 , which shows a $5 \%$ drop in late spring 2010 not associated with any instrumentation change. Third and most importantly, all observed standard deviations as well as the spring 2010 mid-range channel ratio drop are closely related to the magnitude of the lamp irradiance with respect to the magnitude of these channels' background noise. During period 1, the lamp is brighter ( $200 \mathrm{~W})$, and provides channel illumination far above all channels' internal noise. The observed standard deviations in this case reflect only the spectral stability of the lamp irradiance, i.e., about $1.5 \%$ (irradiance ratio). During period 3, the lamp is dimmer $(45 \mathrm{~W})$, and only the standard deviation of the ra- tio of the high-intensity channels reflects the lamp spectral stability. The standard deviation of the other two ranges reflects a combination of the lamp spectral stability and nonnegligible internal background noise. Indeed the mid-range ratio drop in spring 2010 is a direct consequence of the mean background noise reduction in the $407 \mathrm{~nm}$ channel. This apparent reduction was associated with the presence (before spring 2010), then absence (after spring 2010) of undesired isolated spikes in the background noise. Due to of its subtle nature, this feature was never investigated and there is no explanation for it today.

During MOHAVE-2009, the $200 \mathrm{~W}$ lamp initially used was replaced by a dimmer one because the signals acquired by the high-intensity channels were potentially affected by saturation. This hypothesis was indeed verified as the change in the channel ratio associated with the lamp replacement turned out to be very different from those observed on the other two ranges (ratio multiplied by 4 for the high intensity range as opposed to a $20 \%$ increase for the other two ranges, see middle plot of Fig. 17). This finding therefore leads to an important conclusion regarding the general use of a lamp: neither $200 \mathrm{~W}$ nor $45 \mathrm{~W}$ is currently appropriate to obtain an optimized channel ratio for all ranges. In our case, we can (and shall) safely use the Hybrid technique for the mid- and low-intensity ranges only before MOHAVE-2009, and we can (and shall) safely use it for the high-intensity range only after MOHAVE-2009. Ideas for an improved methodology that could be used simultaneously for all ranges are currently being explored.

\section{Conclusions}

A high capability water vapor Raman lidar was developed at the Jet Propulsion Laboratory Table Mountain Facility (California) with the objective of making accurate, routine, longterm water vapor measurements in the UTLS. The system, referred to as 'TMW', was built in 2005 and optimized over the following four years.

Because the overall goal of the TMW instrument is to provide long-term monitoring, several additional considerations (compared to traditional water vapor Raman lidar) were undertaken to insure optimal lidar calibration stability with time. Besides radiosonde, an alternative source of calibration is now systematically used, namely the TPW measurements from a co-located GPS receiver. A third calibration source, namely the TPW measurements from a $22-\mathrm{GHz}$ microwave radiometer (Nedoluha et al., 2011), is also available and will be used as another alternate source. Furthermore, a dedicated calibration method combining a laboratory lamp and radiosondes, and referred to as "hybrid calibration" method, is now used to minimize the cost of launching radiosondes and increase the accuracy and stability of the absolute calibration. 
To support and achieve a full optimization, the MOHAVEI, MOHAVE-II, and MOHAVE-2009 validation campaigns took place in October 2006, 2007 and 2009 respectively. During these campaigns the lidar measurements were extensively compared to operational radiosonde (Vaisala RS92) and Research-grade balloon-borne instruments $(\mathrm{CFH})$

The MOHAVE-I campaign revealed the presence of fluorescence contaminating the lidar signal in its upper part (10$20 \mathrm{~km}$ ). After a first major receiver configuration change in 2007, the MOHAVE-II campaign confirmed the removal of the contaminating fluorescence, but also revealed a substantial loss of signal resulting from this change. After a second major configuration change (summer 2009), the MOHAVE-2009 campaign finally showed that the TMW lidar was brought up to its initial performance expectations, i.e., capable of measuring water vapor mixing ratio in the UTLS with a precision of $10 \%$ or better between $10 \mathrm{~km}$ and $15 \mathrm{~km}$, and reaching $21-22 \mathrm{~km}$ with a degraded precision and vertical resolution.

The latest comparisons with $\mathrm{CFH}$ measurements (MOHAVE-2009) showed excellent agreement throughout the troposphere and UTLS, with mean biases well below the reported measurements uncertainties. The TMW lidar shows a $2 \%$ mean dry bias with $\mathrm{CFH}$ in the lower troposphere, a $3 \%$ mean wet bias in the UTLS, and virtually no bias with the corrected RS92 measurements throughout the troposphere (ground to $18 \mathrm{~km}$ ).

A closer look at the lidar measurement standard deviations above $16 \mathrm{~km}$ during MOHAVE-2009 shows values two to three times larger than that of the $\mathrm{CFH}$. At these altitudes the lidar signals are noise limited and the standard deviation values reflect the precision of the measurements, which therefore provides a good indication of the number of additional lidar measurements needed to achieve the same precision as $\mathrm{CFH}$. It was estimated that one monthly $\mathrm{CFH}$ profile yields a precision in the UTLS equivalent to that of the integrated lidar measurement of one full night per week, or four 2-h-long measurements per week. These estimations show that, with our present target of routinely running TMW two hours per night, 4 nights per week, we can achieve measurements with a precision in the UTLS equivalent to that achieved if launching one CFH per month. Though the TMW lidar is now fully optimized, its overall power-aperture product is well below most contemporary optimums. For example, commercial laser powers today can easily exceed $10 \mathrm{~W}$ at $355 \mathrm{~nm}$ as opposed to $6.5 \mathrm{~W}$ produced by our decade-old laser. Therefore it is not unlikely that a future laser upgrade, together with the upgrade of other components, will bring the precision of the TMW lidar closer to that of the $\mathrm{CFH}$, thus requiring less laser running time to achieve similar levels of precision in the UTLS. Nevertheless, the TMW water vapor Raman lidar has now achieved a comfortable level of maturity and is expected to contribute high-quality long-term, routine profiles of water vapor to the NDACC database, to be released in summer 2011.
Acknowledgements. The work described in this paper was carried out at the Jet Propulsion Laboratory, California Institute of Technology, under agreements with the National Aeronautics and Space Administration. The authors are very grateful to Tony Grigsby and Jeffrey Howe for assisting in the collection of the data presented here.

Edited by: G. Pappalardo

\section{References}

Aspey, R. A., McDermid, I. S., Leblanc, T., Howe, J. W., and Walsh, T. D.: LABVIEW graphical user interface for precision multichannel alignment of Raman lidar at Jet Propulsion Laboratory, Table Mountain Facility, Rev. Sci. Instr., 79, 094502, doi:10.1063/1.2976672, 2008.

Cooney, J.: Remote Measurements of Atmospheric Water Vapor Profiles Using the Raman Component of Laser Backscatter, J. Appl. Meteorol., 9, 182-184, doi:10.1175/15200450(1970)009;0182:rmoawvi2.0.co;2, 1970.

de F. Forster, P. M. and Shine, K. P.: Stratospheric water vapour changes as a possible contributor to observed stratospheric cooling, Geophys. Res. Lett., 26, 3309-3312, doi:10.1029/1999g1010487, 1999.

Donovan, D. P., Whiteway, J. A., and Carswell, A. I.: Correction for nonlinear photon-counting effects in lidar systems, Appl. Opt., 32, 6742-6753, 1993.

Hinkley, E.: Topics in Applied Physics, Vol. 14, chap. Laser monitoring of the atmosphere, p. 380 pp, Springer, New York, 1976.

Hurst, D. F., Oltmans, S. J., Vömel, H., Rosenlof, K. H., Davis, S. M., Ray, E. A., Hall, E. G., and Jordan, A. F.: Stratospheric water vapor trends over Boulder, Colorado: Analysis of the 30 year Boulder record, J. Geophys. Res., 116, D02306, doi:10.1029/2010jd015065, 2011.

Kaiser, J. F. and Reed, W. A.: Data Smoothing Using Low-Pass Digital-Filters, Rev. Sci. Instr., 48, 1447-1457, 1977.

Leblanc, T. and McDermid, I. S.: Accuracy of Raman lidar water vapor calibration and its applicability to long-term measurements, Appl. Opt., 47, 5592-5603, 2008.

Leblanc, T., McDermid, I. S., and Aspey, R. A.: First-Year Operation of a New Water Vapor Raman Lidar at the JPL Table Mountain Facility, California, J. Atmos. Ocean. Tech., 25, 1454-1462, doi:10.1175/2007JTECHA978.1, 2008a.

Leblanc, T., McDermid, I. S., McGee, T. G., Twigg, L., Sumnicht, G., Whiteman, D. N., Rush, K., Cadirola, M., Venable, D., Connell, R., Demoz, B., Vömel, H., and Miloshevich, L.: Measurements of humidity in the atmosphere and validation experiments (MOHAVE, MOHAVE II): Results overview, Reviewed and Revised Papers of The 24th International Laser Radar Conference, Boulder, CO, 23-27 June 2008, 1013-1016, 2008b.

Leblanc, T., Walsh, T. D., McDermid, I. S., Toon, G. C., Blavier, J.-F., Haines, B., Read, W. G., Herman, B., Fetzer, E., Sander, S., Pongetti, T., Whiteman, D. N., McGee, T. G., Twigg, L., Sumnicht, G., Venable, D., Calhoun, M., Dirisu, A., Hurst, D., Jordan, A., Hall, E., Miloshevich, L., Vmel, H., Straub, C., Kampfer, N., Nedoluha, G. E., Gomez, R. M., Holub, K., Gutman, S., Braun, J., Vanhove, T., Stiller, G., and Hauchecorne, A.: Measurements of Humidity in the Atmosphere and Validation Experiments (MOHAVE)-2009: overview of campaign 
operations and results, Atmos. Meas. Tech., 4, 2579-2605, doi:10.5194/amt-4-2579-2011, 2011.

McDermid, I. S., Beyerle, G., Haner, D. A., and Leblanc, T.: Redesign and improved performance of the tropospheric ozone lidar at the Jet Propulsion Laboratory Table Mountain Facility, Appl. Opt., 41, 7550-7555, 2002.

McGee, T. G., Twigg, L., and Sumnicht, G.: STROZ lidar measurements of ozone, temperature and water vapor during the MOHAVE 2009 campaign, Atmos. Meas. Technol. Disc., 4, in preparation, 2011.

McGee, T. J., Whiteman, D., Ferrare, R., Butler, J. J., and Burris, J. F.: STROZ LITE - STRatospheric OZone Lidar Trailer Experiment, Opt. Engin., 30, 31-39, 1991.

Measures, R. M.: Laser remote sensing: fundamentals and applications, Krieger Pub. Co., Malabar, FL, 1992.

Melfi, S. H., Lawrence, J. D., and McCormic, Mp.: Observation of Raman Scattering by Water Vapor in Atmosphere, Appl. Phys. Lett., 15, 295-297, doi:10.1063/1.1653005, 1969.

Miloshevich, L. M., Paukkunen, A., Vömel, H., and Oltmans, S. J.: Development and Validation of a Time-Lag Correction for Vaisala Radiosonde Humidity Measurements, J. Atmos. Ocean. Tech., 21, 1305-1327, doi:10.1175/15200426(2004)021;1305:DAVOAT $; 2.0 . C O ; 2,2004$.

Miloshevich, L. M., Vömel, H., Whiteman, D. N., and Leblanc, T.: Accuracy assessment and correction of Vaisala RS92 radiosonde water vapor measurements, J. Geophys. Res., 114, D11305, doi:10.1029/2008jd011565, 2009.

Nedoluha, G. E., Gomez, R. M., Hicks, B. C., Helmboldt, J., Bevilacqua, R. M., and Lambert, A.: Ground-based microwave measurements of water vapor from the midstratosphere to the mesosphere, J. Geophys. Res., 116, D02309, doi:10.1029/2010jd014728, 2011

Oltmans, S. J. and Hofmann, D. J.: Increase in lower-stratospheric water-vapor at a mid-latitude Northern-Hemisphere site from 1981 to 1994, Nature, 374, 146-149, 1995.

Sherlock, V., Garnier, A., Hauchecorne, A., and Keckhut, P.: Implementation and Validation of a Raman Lidar Measurement of Middle and Upper Tropospheric Water Vapor, Appl. Opt., 38, 5838-5850, 1999a.

Sherlock, V., Hauchecorne, A., and Lenoble, J.: Methodology for the Independent Calibration of Raman Backscatter Water-Vapor Lidar Systems, Appl. Opt., 38, 5816-5837, 1999b.

Stiller, G. P., Kiefer, M., Eckert, E., von Clarmann, T., Kellmann, S., García-Comas, M., Funke, B., Leblanc, T., Fetzer, E., Froidevaux, L., Gomez, M., Hall, E., Hurst, D., Jordan, A., Kämpfer, N., Lambert, A., McDermid, I. S., McGee, T., Miloshevich, L., Nedoluha, G., Read, W., Schneider, M., Schwartz, M., Straub, C., Toon, G., Twigg, L. W., Walker, K., and Whiteman, D. N.: Validation of MIPAS IMK/IAA temperature, water vapor, and ozone profiles with MOHAVE-2009 campaign measurements, Atmos. Meas. Tech. Discuss., 4, 4403-4472, doi:10.5194/amtd4-4403-2011, 2011.
Toon, G., et al.: The MkIV Infrared Fourier-Transform Spectrometer measurements during MOHAVE-2009, Atmos. Meas. Technol. Disc., 4, in preparation, 2011.

Turner, D. D. and Goldsmith, J. E. M.: Twenty-Four-Hour Raman Lidar Water Vapor Measurements during the Atmospheric Radiation Measurement Program's 1996 and 1997 Water Vapor Intensive Observation Periods, J. Atmos. Ocean. Tech., 16, 1062-1076, doi:10.1175/15200426(1999)016;1062:TFHRLW $i 2.0 . C O ; 2,1999$.

Vaughan, G., Wareing, D. P., Thomas, L., and Mitev, V.: Humidity Measurements In The Free Troposphere Using Raman Backscatter, Q. J. Roy. Meteorol. Soc., 114, 1471-1484, 1988.

Vömel, H., David, D. E., and Smith, K.: Accuracy of tropospheric and stratospheric water vapor measurements by the cryogenic frost point hygrometer: Instrumental details and observations, J. Geophys. Res., 112, D08305, doi:10.1029/2006jd007224, 2007.

Whiteman, D. N.: Examination of the Traditional Raman Lidar Technique. II. Evaluating the Ratios for Water Vapor and Aerosols, Appl. Opt., 42, 2593-2608, 2003.

Whiteman, D. N., Demoz, B., Rush, K., Schwemmer, G., Gentry, B., Di Girolamo, P., Comer, J., Veselovskii, I., Evans, K., Melfi, S. H., Wang, Z., Cadirola, M., Mielke, B., Venable, D., and Van Hove, T.: Raman Lidar Measurements during the International $\mathrm{H}_{2} \mathrm{O}$ Project. Part I: Instrumentation and Analysis Techniques, J. Atmos. Ocean. Tech., 23, 157-169, doi:10.1175/JTECH1838.1, 2006.

Whiteman, D. N., Veselovskii, I., Cadirola, M., Rush, K., Comer, J., Potter, J. R., and Tola, R.: Demonstration measurements of water vapor, cirrus clouds, and carbon dioxide using a highperformance Raman lidar, J. Atmos. Ocean. Tech., 24, 13771388, doi:10.1175/jtech2058.1, 2007.

Whiteman, D. N., Rush, K., Rabenhorst, S., Welch, W., Cadirola, M., McIntire, G., Russo, F., Adam, M., Venable, D., Connell, R., Veselovskii, I., Forno, R., Mielke, B., Stein, B., Leblanc, T., McDermid, S., and Vomel, H.: Airborne and Ground-Based Measurements Using a High-Performance Raman Lidar, J. Atmos. Oceanic Tech., 27, 1781-1801, doi:10.1175/2010jtecha1391.1, 2010.

Whiteman, D. N., et al. (2011): Development of a Correction Technique for Raman Water Vapor Lidar Signal Dependent Wet Bias and Application to Upper Tropospheric Retrievals, Atmos. Meas. Technol. Disc., 4, in preparation, 2011. 